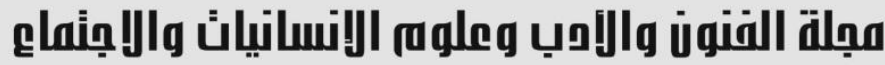

Journal of Arts, Literature, Humanities and Social Sciences
www.jalhss.com

\section{شرائط تولية القضاء في الفقه والقانون}

\author{
نجيب محسن شاكر العساف وان \\ جامعة وان يوزونجوييل

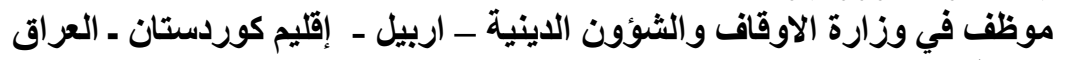

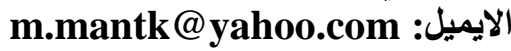

من المعلوم أن ولاية القضاء من أهم و أعظم دعائم الحكم في الدولة فهي صنعة الانبياء و الرسل، و هناك وفاك

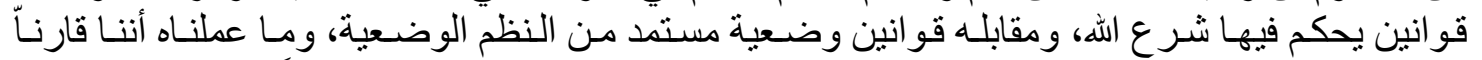

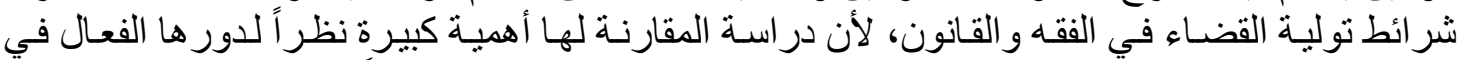

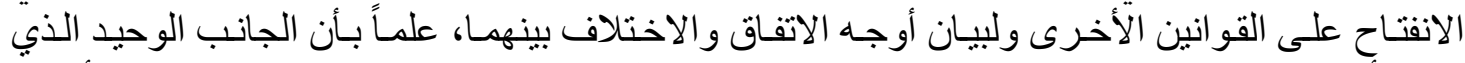

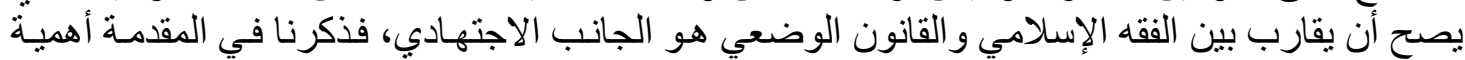

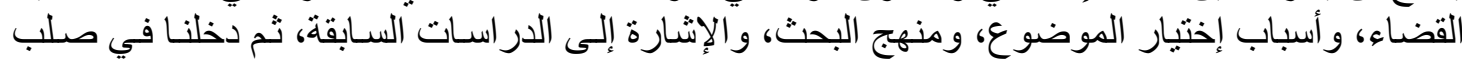

$$
\text { الموضوع فكانت مكونة من مبحثين. }
$$

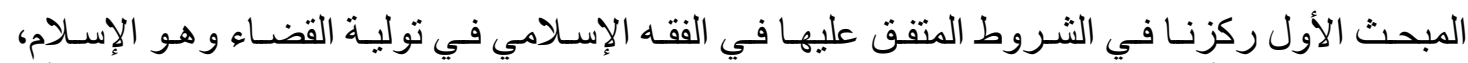

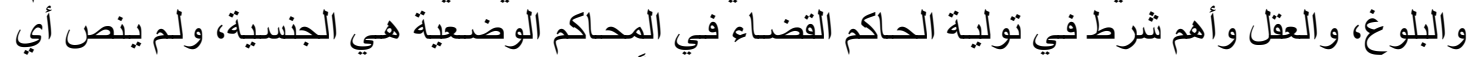

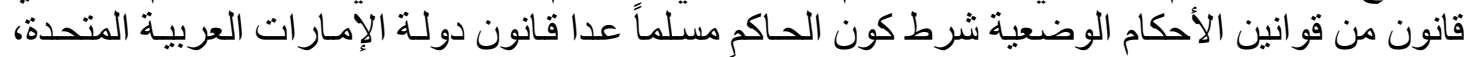
فتمتع القاضي بجنسية البلا الذي يعمل به يكون شرطاً غير مو الفق لأحكام الثريعة الإسلامية.

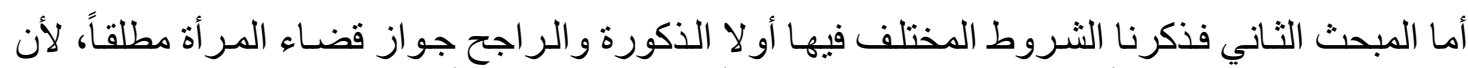

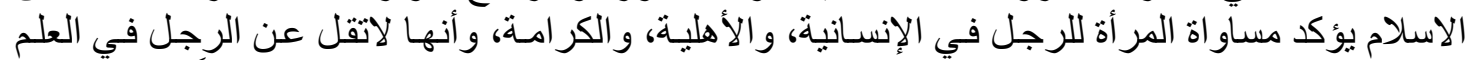

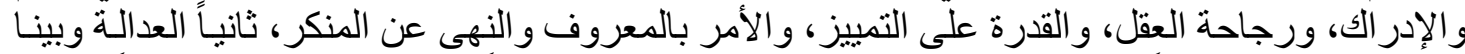

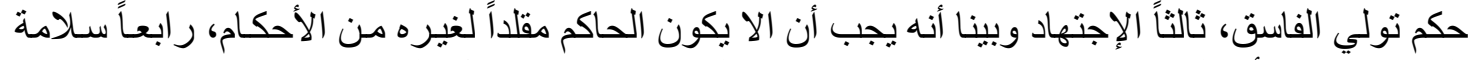

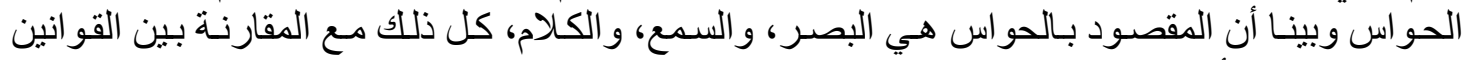

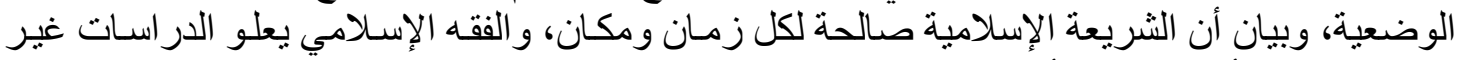

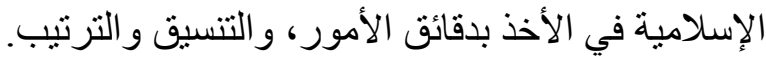
و هدف البحث إبراز وبيان معرفة الثر ائط المطلوبة في تولية القضاء في الفقه و القانون. 


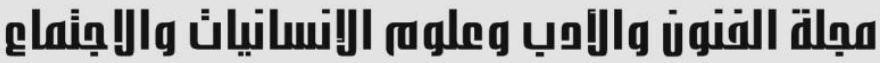 Journal of Arts, Literature, Humanities and Social Sciences www.jalhss.com \\ Conditions of the Judiciary in Jurisprudence and Law
}

\author{
Najip Muhsin Shakir Al-Assaf \\ Ph.D in Islamic Law, Wan Yuzunuyil University \\ An Employee at the Ministry Of Awqaf and Religious Affairs - Erbil Kurdistan \\ Region - Iraq \\ Email: m.mantk@yahoo.com
}

\begin{abstract}
It is known that the jurisdiction of the judiciary is one of the most important and greatest pillars of governance in the state, it is the work of the prophets and messengers, and there are laws in which God's law governs, and in return for positive laws derived from positive systems, and what we have done is that we have compared the tapes of assuming the judiciary in jurisprudence and law, because the study of comparison has great importance in view of For its effective role in opening up to other laws and showing aspects of agreement and the difference between them, bearing in mind that the only aspect that is correct to converge between Islamic jurisprudence and positive law is the jurisprudential side, so we mentioned in the introduction the importance of the judiciary, the reasons for choosing the topic, the research method, and reference to the studies Bug, and then we entered the heart of the matter was made up of two sections. The first topic focused on the conditions agreed upon in Islamic jurisprudence in the assumption of the judiciary, which is Islam, puberty, and reason and the most important condition in the ruler's assumption of the judiciary in statutory courts is nationality, and no law of statutory provisions stipulated that the ruler be a Muslim except the law of the United Arab Emirates, The judge's enjoyment of the nationality of the country in which he works is a condition inconsistent with the provisions of Islamic Sharia. As for the second topic, we mentioned the different conditions in it, firstly, masculinity and the preponderant that a woman can be completely judged, because Islam affirms the equality of women in men in humanity, competence, and dignity, and that they are no less than men in knowledge and awareness, the preponderance of reason, the ability to distinguish, and the promotion of virtue and forbidding what is wrong, secondly Justice and we have clarified the ruling on assuming immorality, thirdly, ijtihad and we have indicated that the ruler should not be imitating other rulings. Fourthly, the integrity of the senses and we have indicated that the intended senses are sight, hearing, and speech, all with the comparison between statutory laws, and a statement that Islamic law is valid for every time and place, Islamic jurisprudence is above non-Islamic studies in a few minutes, taking things, coordination and arrangement. The aim of the research is to highlight and demonstrate knowledge of the tapes required in the judiciary in jurisprudence and law.
\end{abstract}

Keywords: jurisdiction, Islamic jurisprudence, positive laws, judge. 


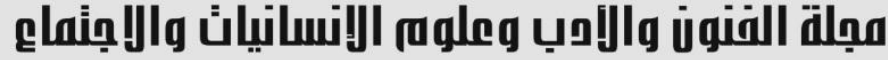

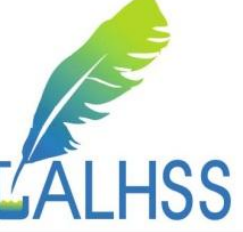

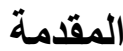

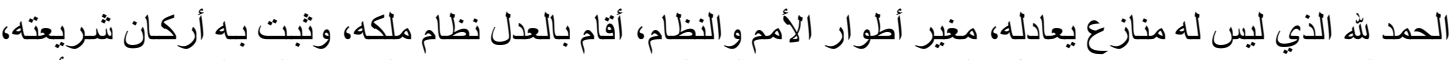

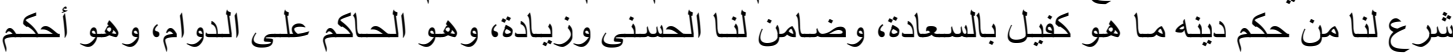

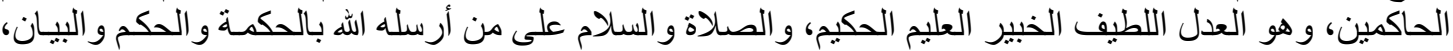
و على آله و أصحابه الذين هذبو ا أعمالهم فكانت غرة وجه الإسلام، على مر الأيام بالحكمة و العدل والإحسان. وبعد:

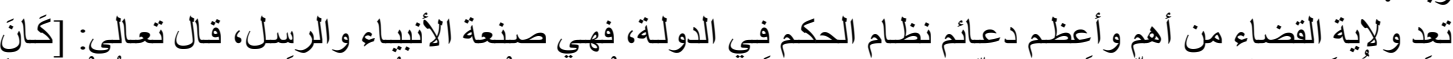

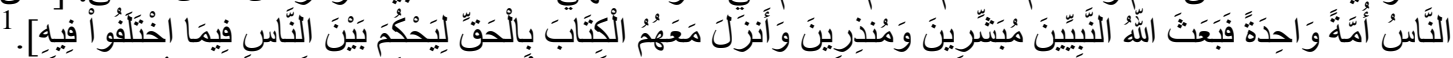

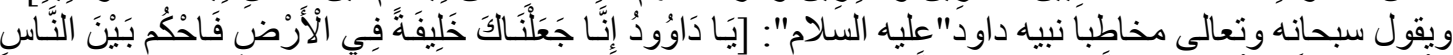

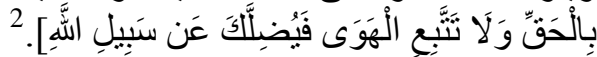

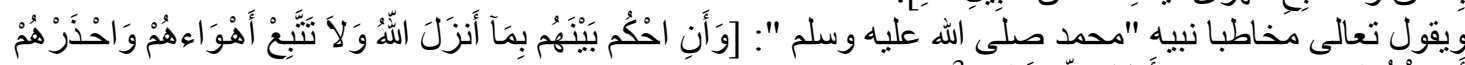

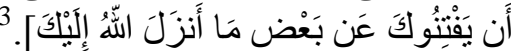

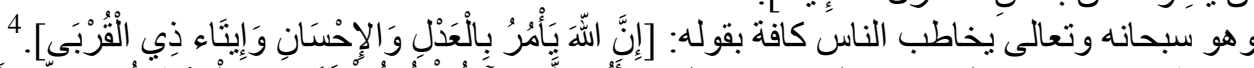

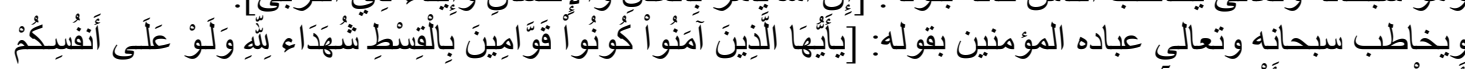

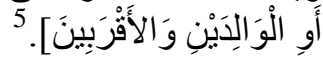

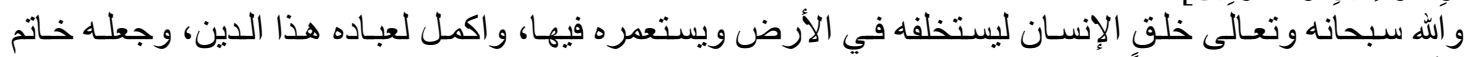

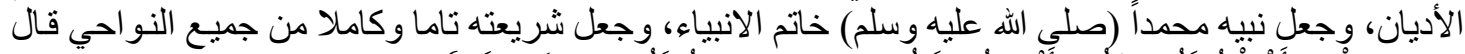

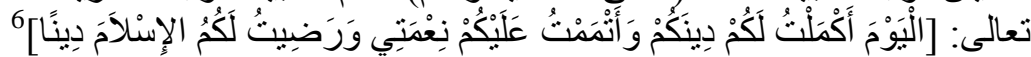

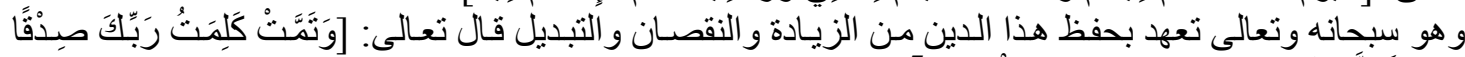

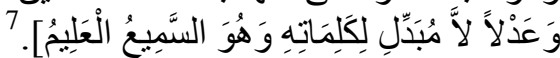

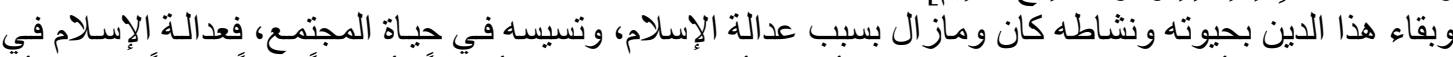

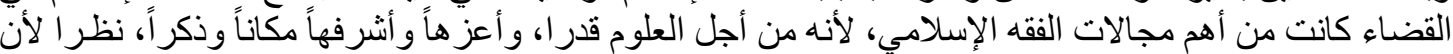

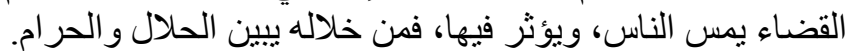

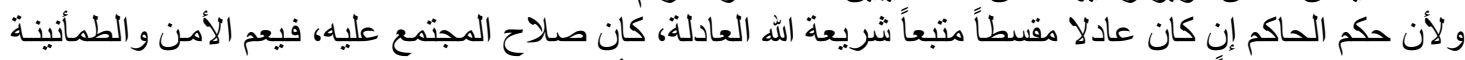

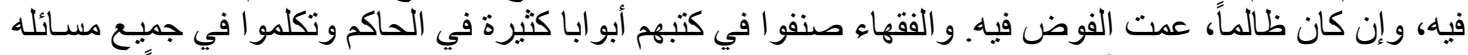

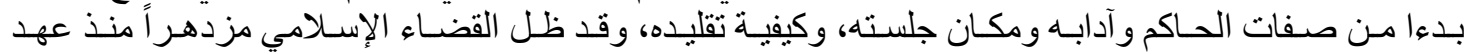

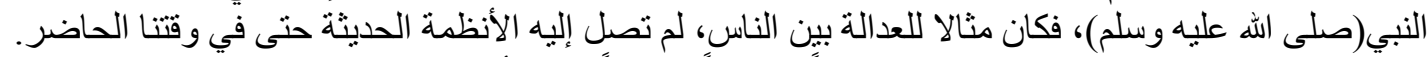

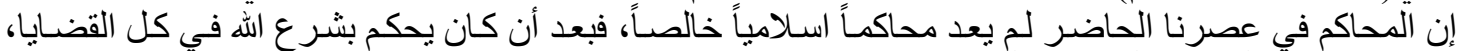

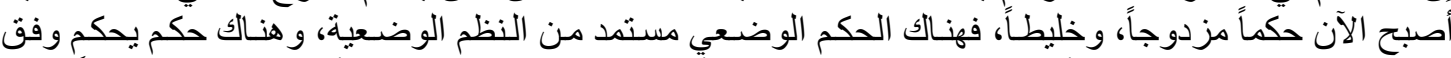

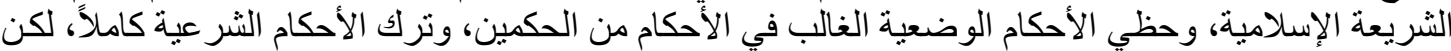

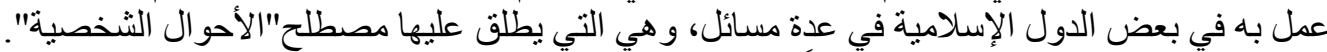

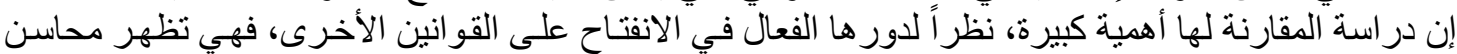

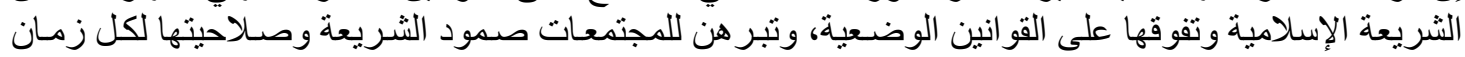

فكانت رغبتي في كتابة هذا الموضوع تبيين أوجه الاختلاف و التشابه بين الثريعة الإسـامية والقو انين الوضعية

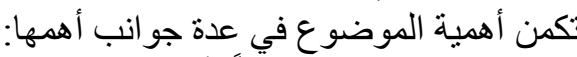
1ـ تعريف المسلمين عموماً بأحكام نولية القضاء البهاء في الفقه الاسلامي و القانون الوضعي.

2- ارتباط الموضوع بالو اقع وحاجة الناس إليه.

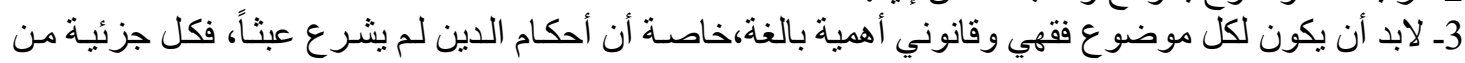




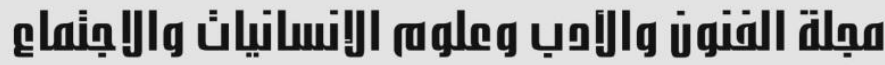

Journal of Arts, Literature, Humanities and Social Sciences
www.jalhss.com

5ـ جاءت هذه الرسالة لتلقي الضوء على در اسة أحكام تولي القضـاء، وتكثف عما يتصل بها كثفاً دالاً، يضيف

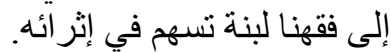

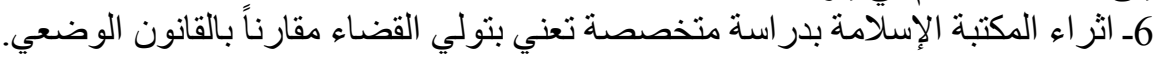

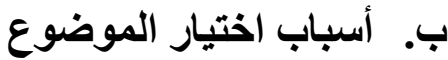

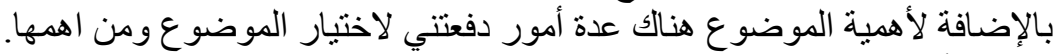

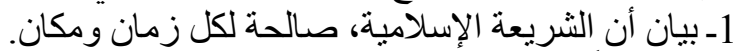
2- إن كثير اً من الأحكام الوضعية مستمدة من الثرية الثريعة الإسلامية.

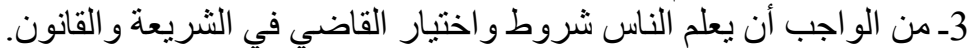

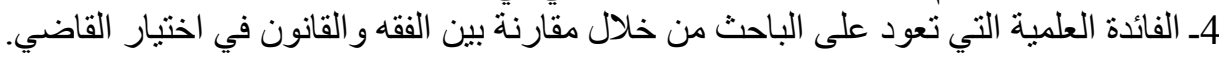

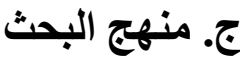

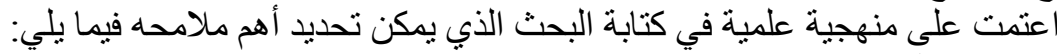

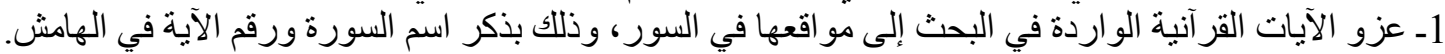

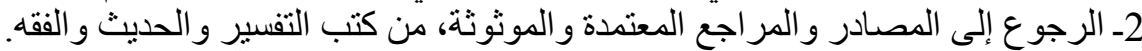

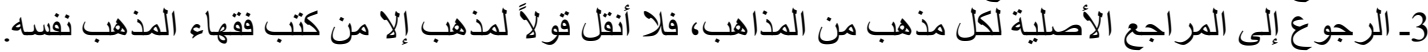

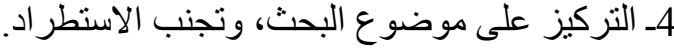

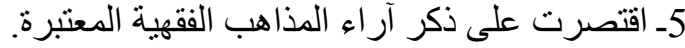
6- 2 - تجنب ذكر الأقو ال الثناذة.

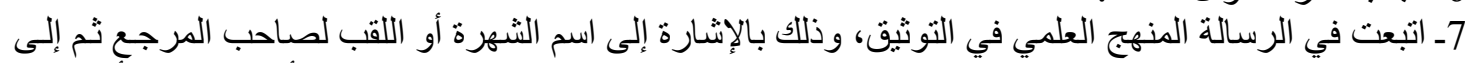

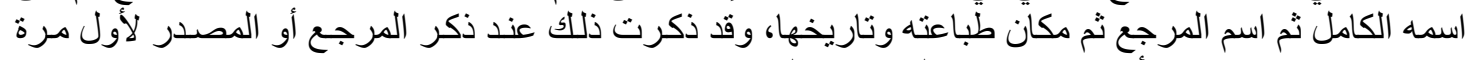

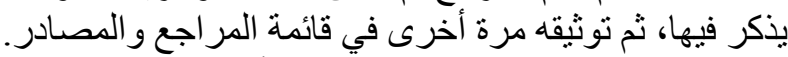

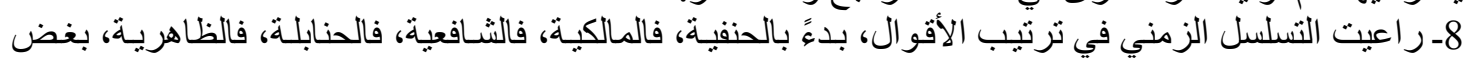

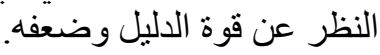

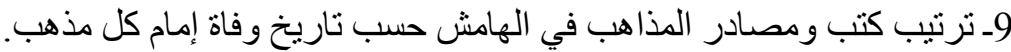

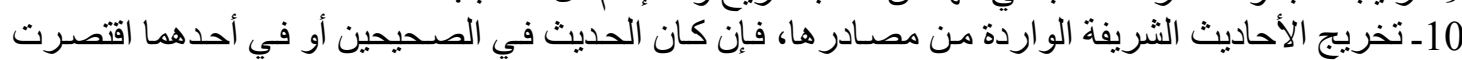

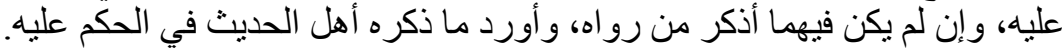
11 اتبعت البحث بفهرس المر اجع و المصنادر.

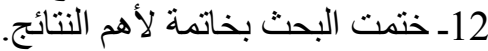
د. د. الاراسات السابقة

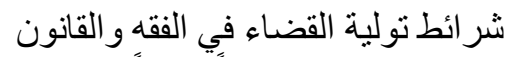
لم يبحث من قبـل بحثناً علمياً متخصصهـاً شـاملاً مقارنـاً بالقانون المصري و العر اقي ولم أعلم أن أحداً قد تتاولها بشكلها التفصيلي.

\section{تثصيب القاضي في الفقه الإسلامي والقانون الوضعي}

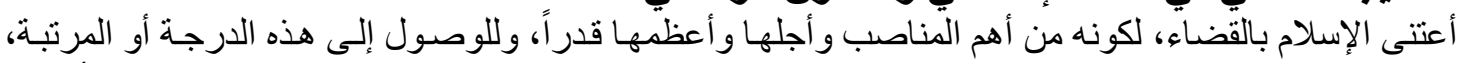

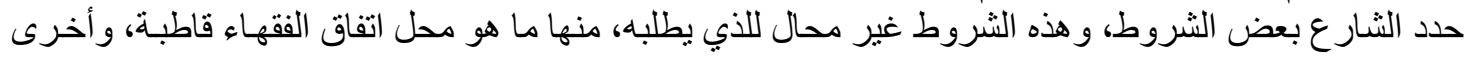
محل خلاف بينهم وسنتكلم ذلك في مبحثين. 


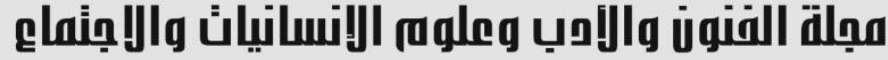

Journal of Arts, Literature, Humanities and Social Sciences
www.jalhss.com
Volume (51) Abril 2020

\section{المبحث الأول \\ الشروط المتفق عليها في الفقه الإسلامي}

من الثروط المتفق عليها في الفقه الإسلامي، الاسلام و البلوغ و العقل لذا سنتحدث على ذلك في ثلاثة مطالب:

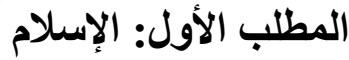

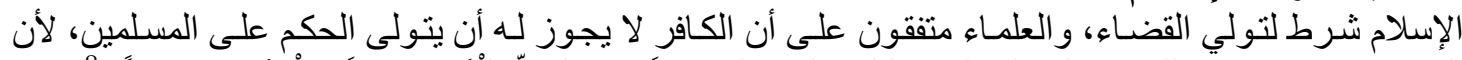

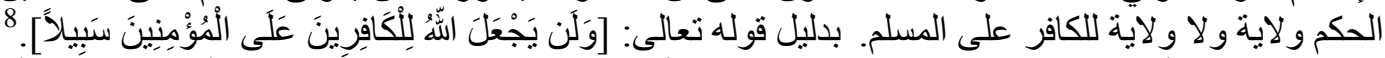

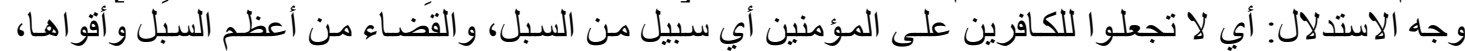

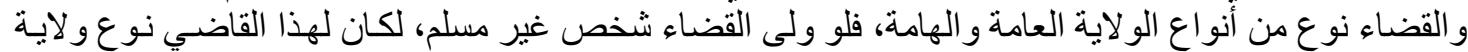

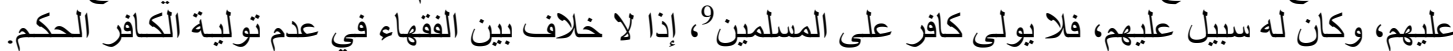

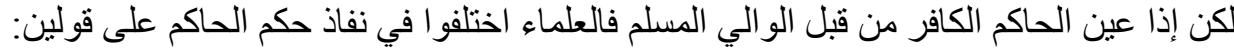

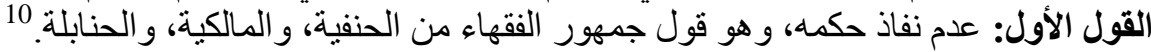
القول الثاني: نفاذ حكمه سياسة لا ديانة، وهول هول مذهب الثان الثافعية. 11

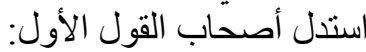

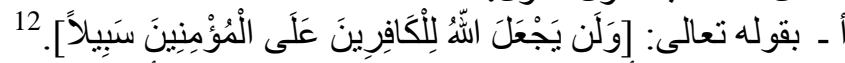

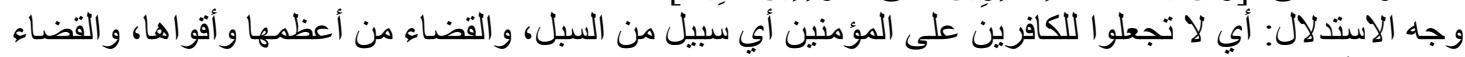

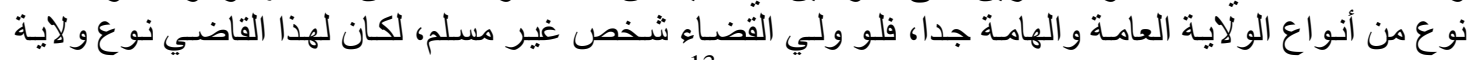

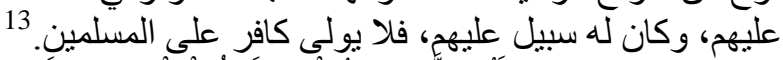

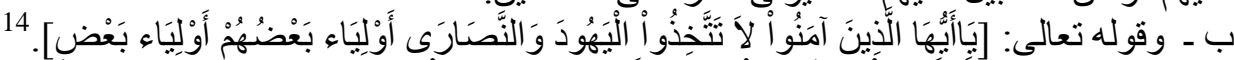

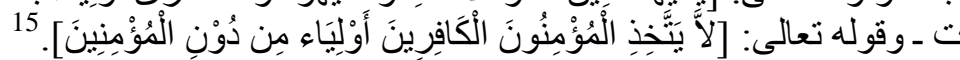

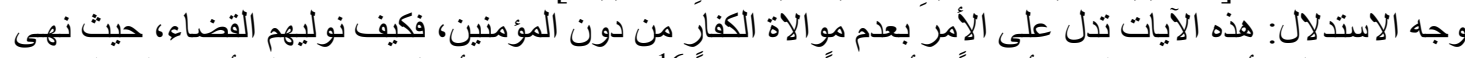

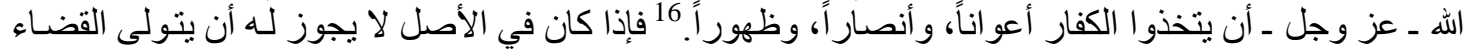

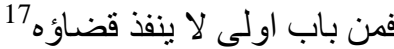

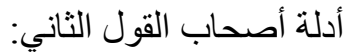

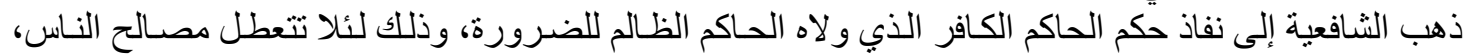

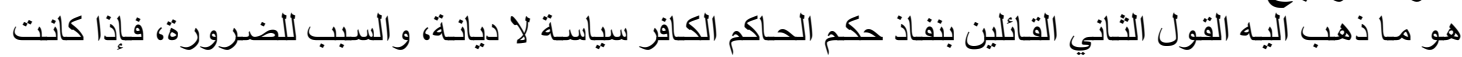
الضرورة في ذلك الوقت، فالآن في هذا الوقت العصيب الضرورة الضئ الولى حتى إذا امتنع المسلمون من الالتز ام فإنهر

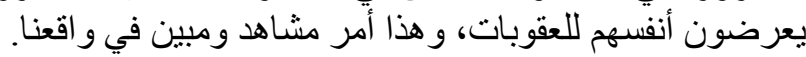

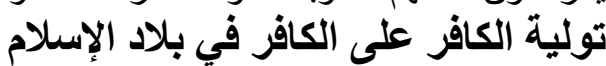
إذا ولي الكافر الحكم على الكافر لكن كان نطاق حكمهـ في بـلاد الإسـلام، فالعلمـاء اختلفو ا في جواز تقليده الحكم

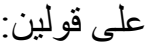
القول الأول: عدم جوازين: هول وهو قول جمهور الفقهاء من المالكية ، و الثشافعية ، و الحنابلة.19.

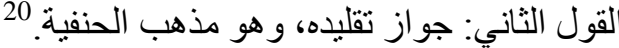

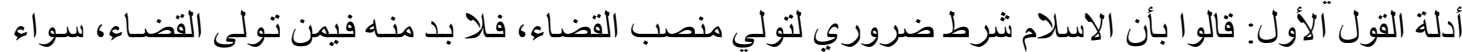
كان قضاؤه على المسلمين أم غير المسلمين.

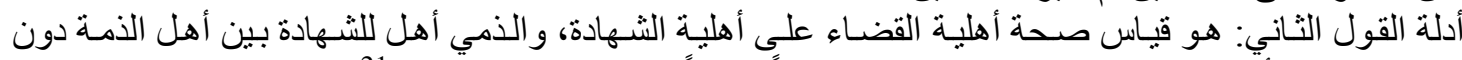

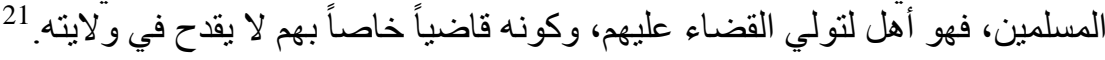




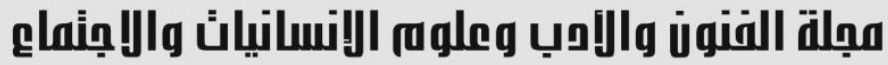

Journal of Arts, Literature, Humanities and Social Sciences
www.jalhss.com

الراجح

هو ما ذهب إليه الحنفية، وذللك قياساً على الثهادة، وللأعر اف الجارية في تقليد الكفار بين أهل دينهم، و هذا هو

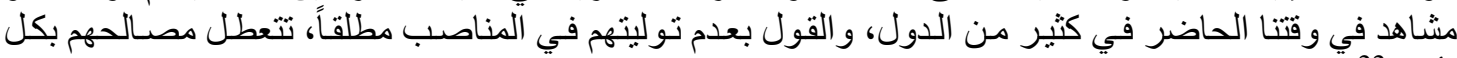
تأكبد.

\section{موقف القانون الوضعي في شرط الإسلام}

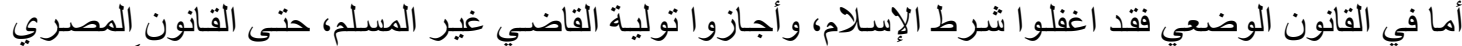

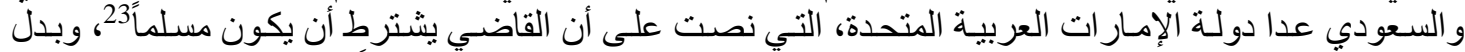

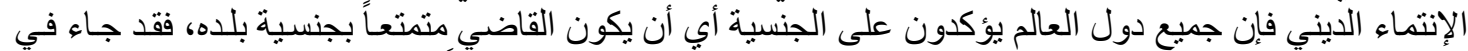

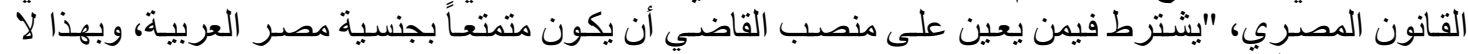

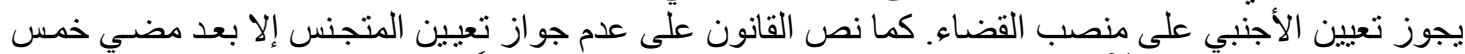

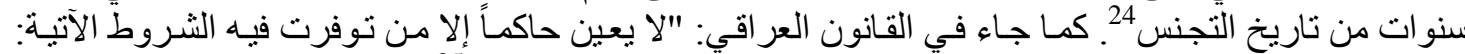

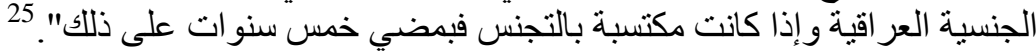

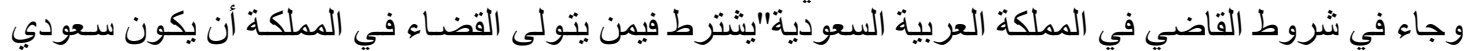

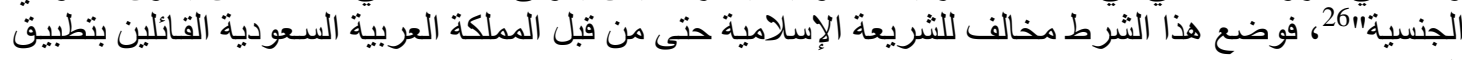
الثريعة الإسلامية.

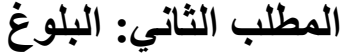

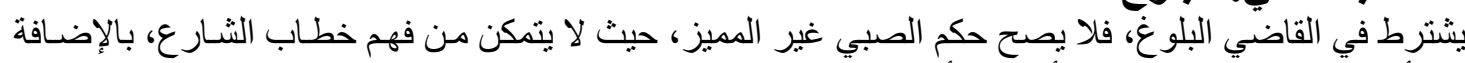

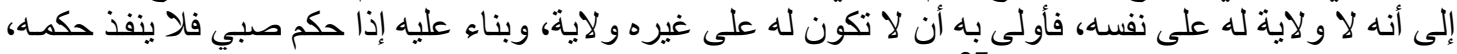

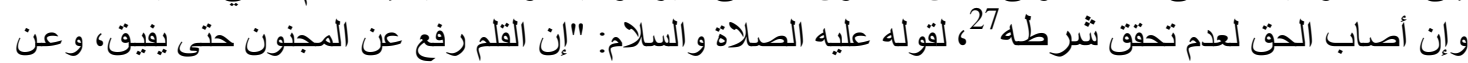

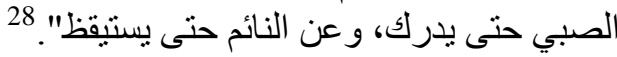
موقف القانون الوضعي في البلوغ الون النون

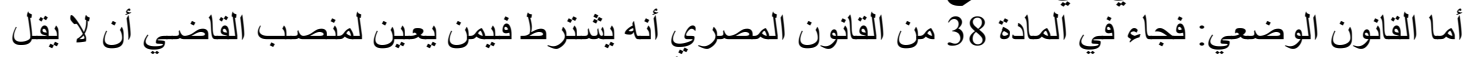

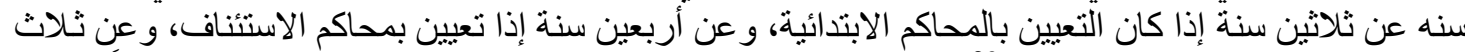

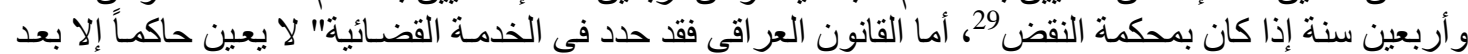

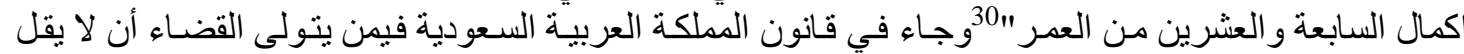

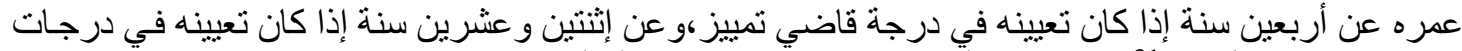

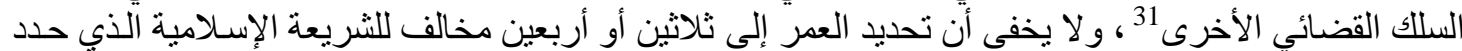
بالبلوغ.

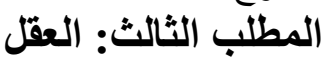

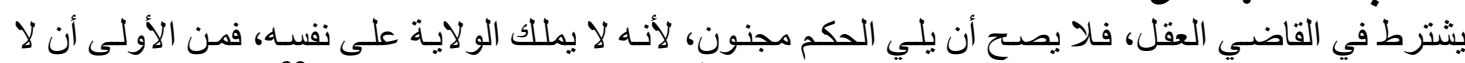

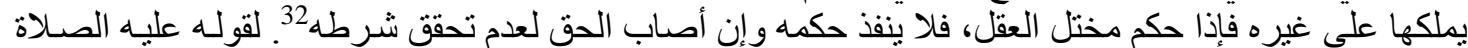

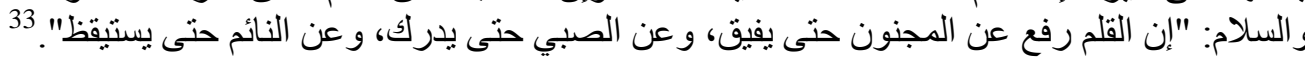

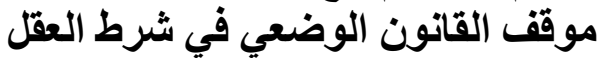

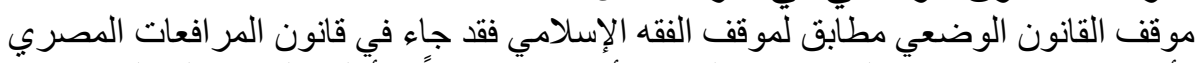

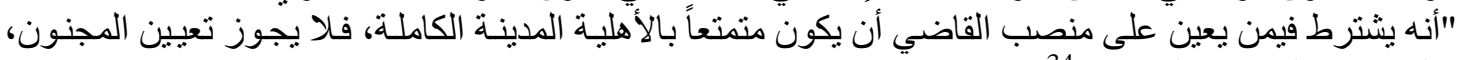
و الصببي، و السفيه، و المعتوه".

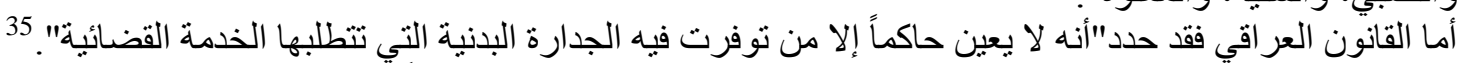

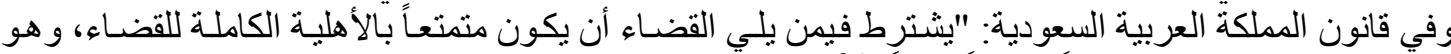

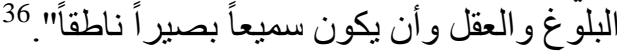




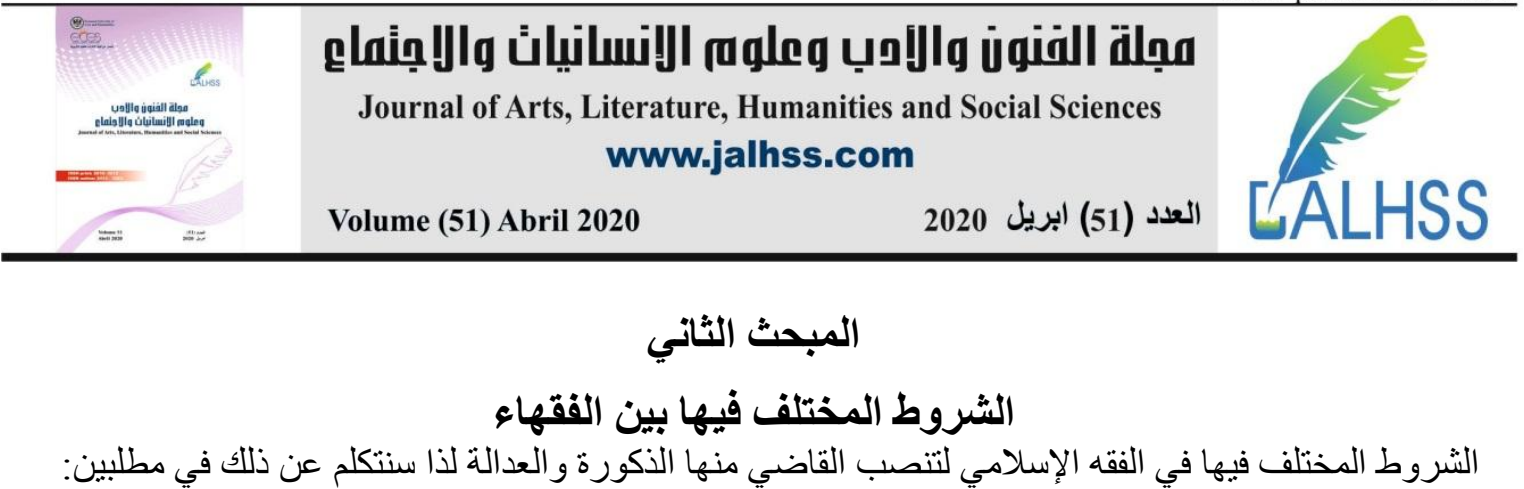

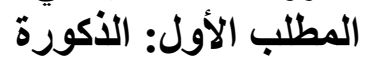

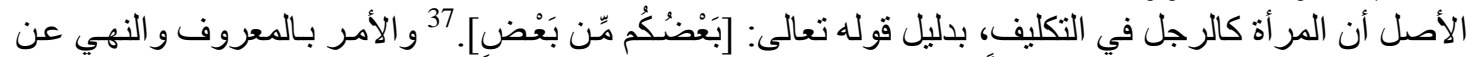

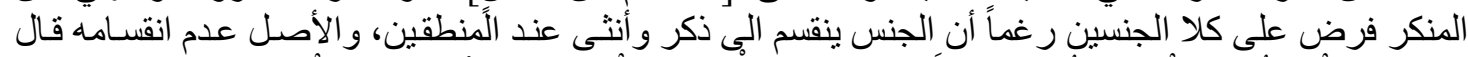

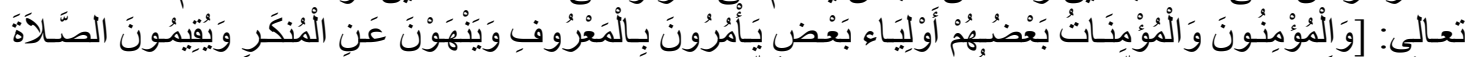

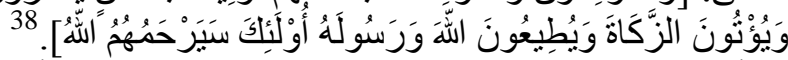

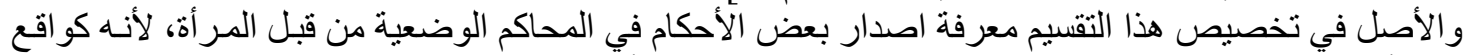

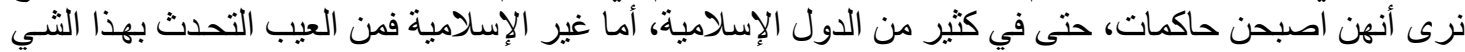

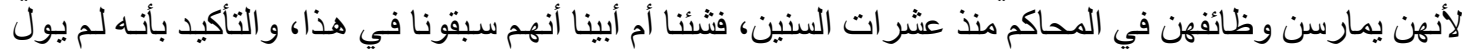

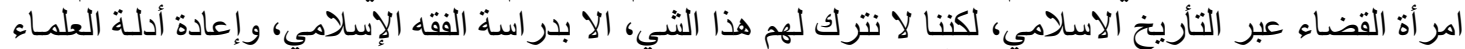

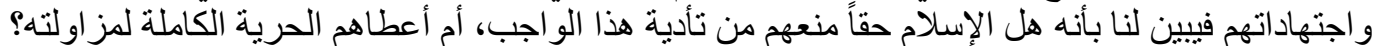

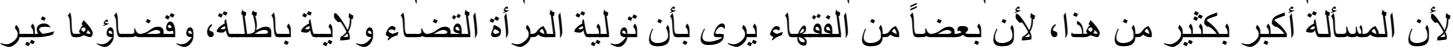

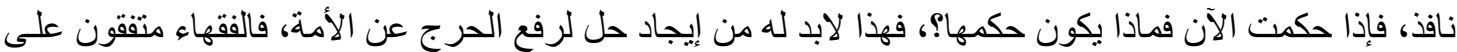

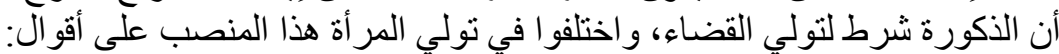

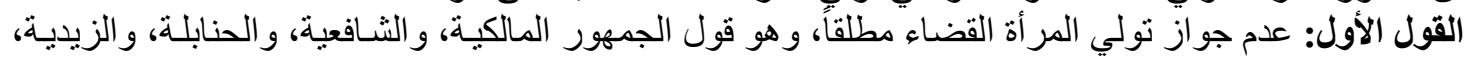

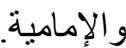

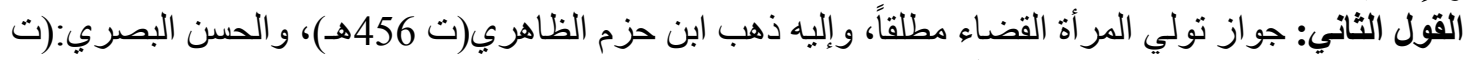

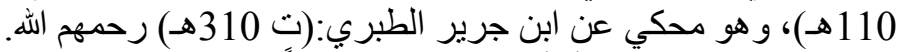

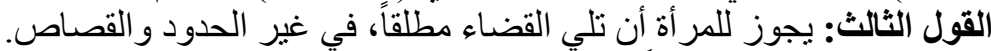

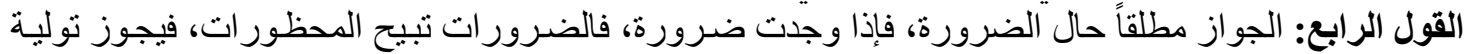

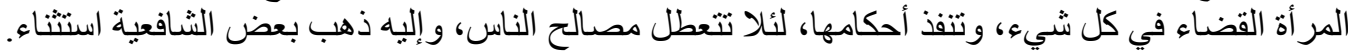

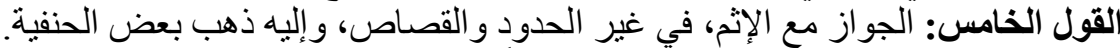

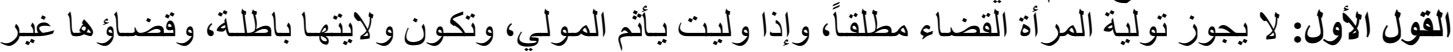

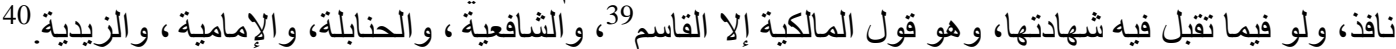

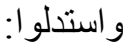

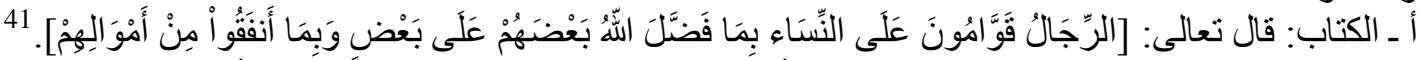

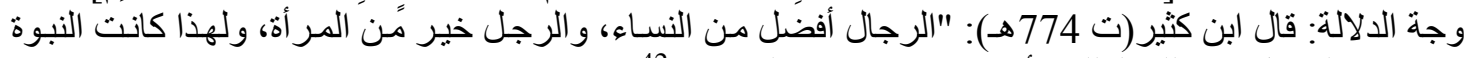

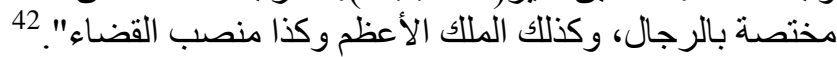

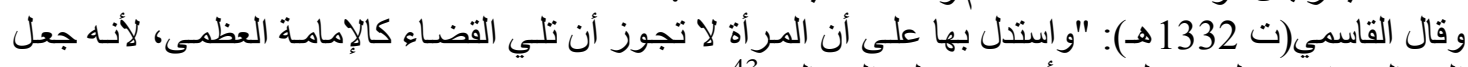
الرجال قو امين عليهن، فلم يجز أن يقمن على الرجال الرجال".

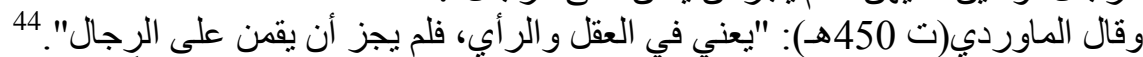

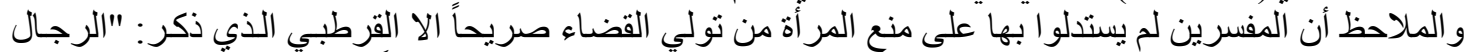

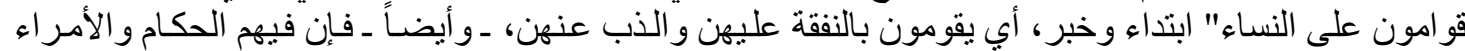

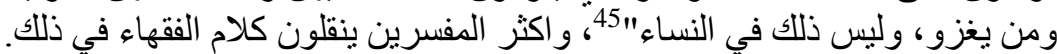

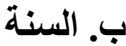

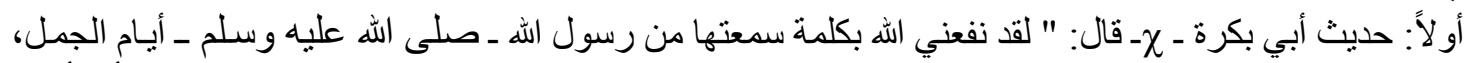

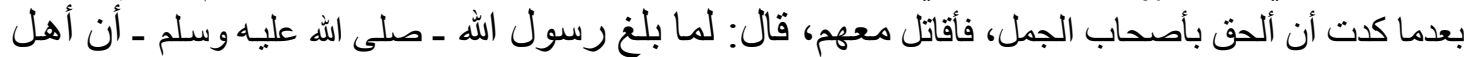

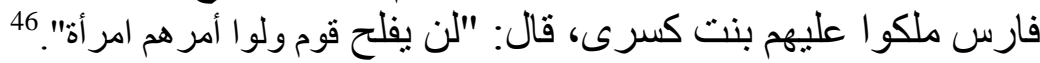

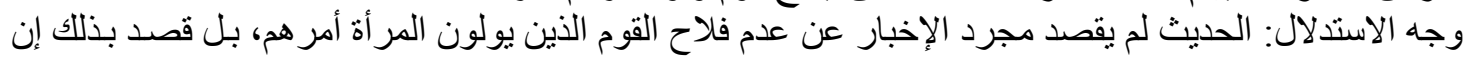

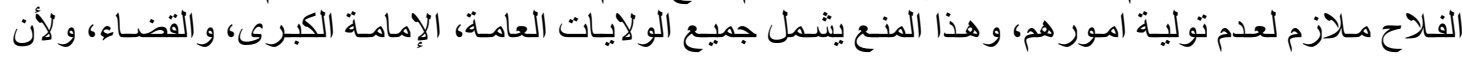




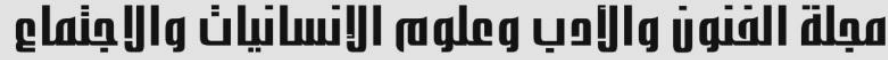

Journal of Arts, Literature, Humanities and Social Sciences
www.jalhss.com

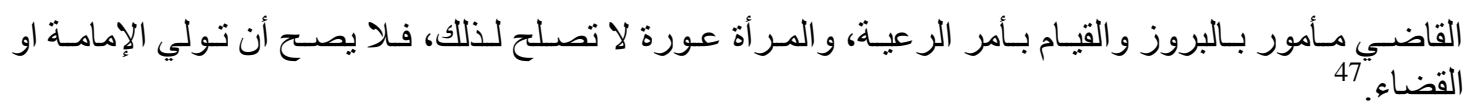
واجيب: أن هذا الاستـلال غير صحيح، لأن الحديث خـارج عن محل النزاع، لأن ذلك في الولايـة والإمامـة

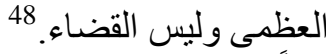

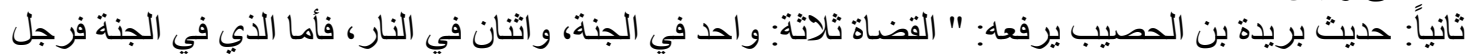

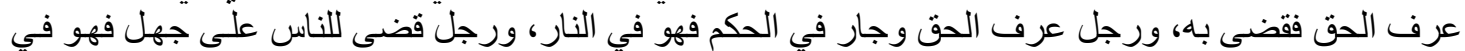

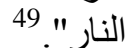
وجه الدلالة: قوله فيه: "فرجل... ورجل"، فإن هذا يفيد حصر القضاء في الرجال، ويخرج بمفهومـه النسـاء، فهن لا يصلحن للقضاء. يقول الثوكاني(ت 1205 هـ): "و استدل المصنف ـ أيضاً ـ على ذلك بحديث بريدة المذكور في الباب لقوله فيه:

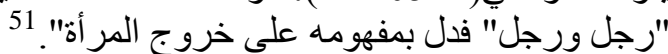

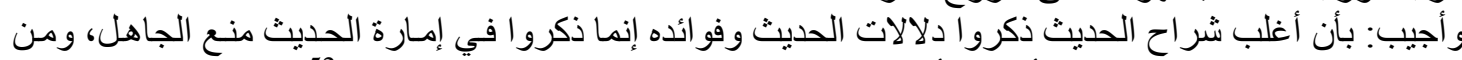

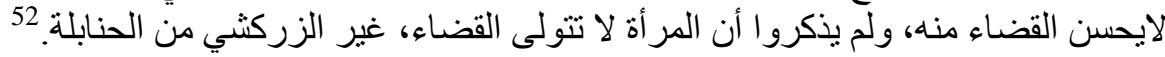

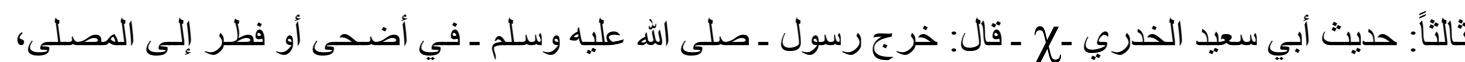

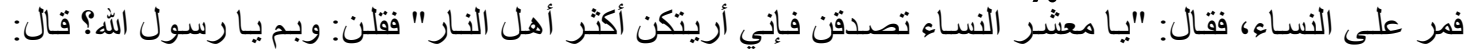

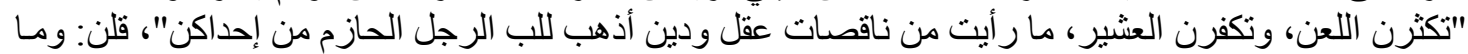

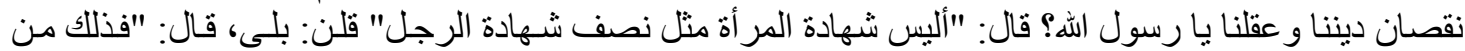

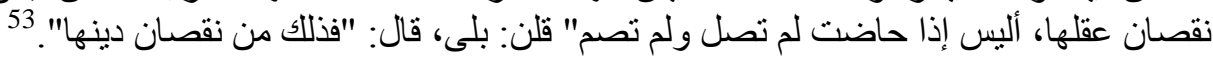

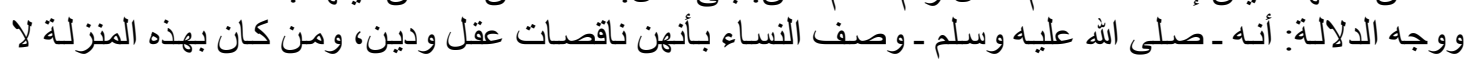

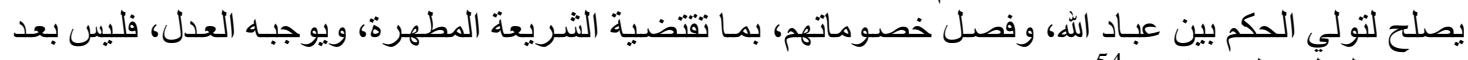
نقصان العقل و الدين شيء.

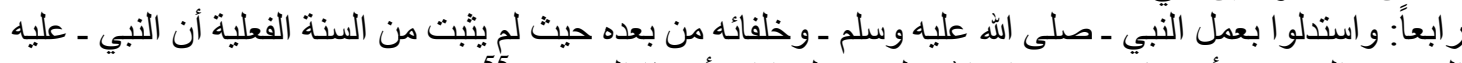

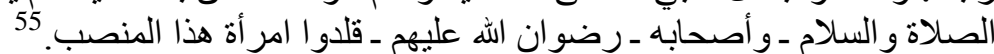

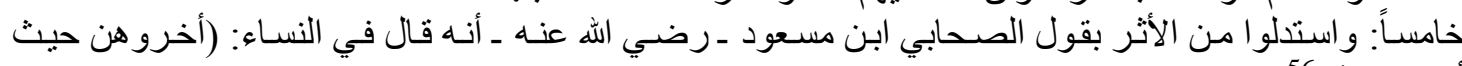
أخر هن الهة) يقول القر افي: (ت 684هـ) معلقاً على هذا الأثر : "و هذا غاية النقص لهن، منعت أن تقوم بجنب الرجل في الصـلاة

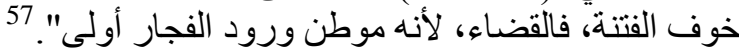

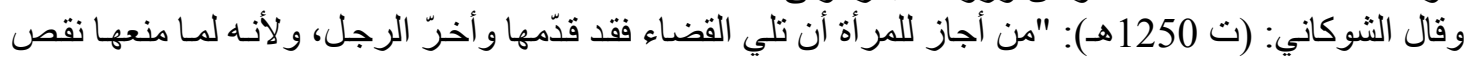

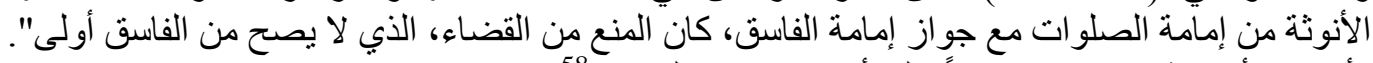

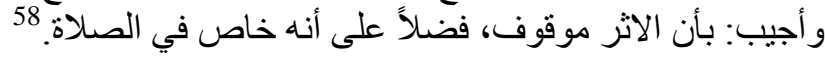

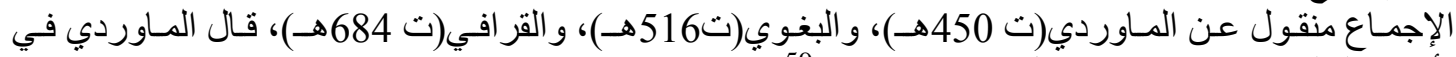

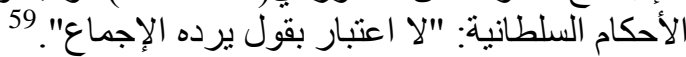

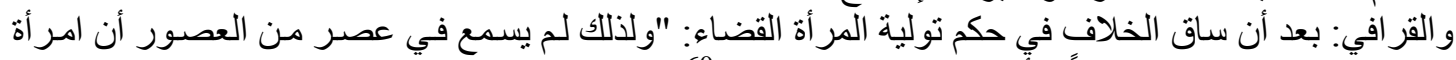
وليت القضاء فكان ذلك إجماعاً، لأنه غير سبيل الفيل المؤمنين".

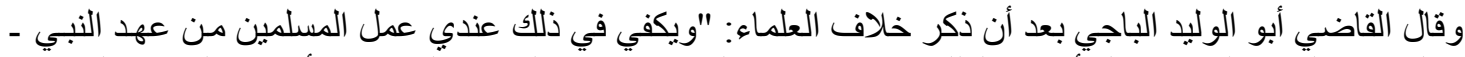

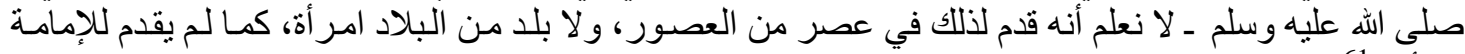

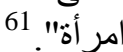
وقال ابن قدامة(ت620هـ):"لم يولّ النبي ـ صلى الله عليه وسلم ـ و لا أحد من خلفائه، و لا من بعدهم، امر أة قضاء

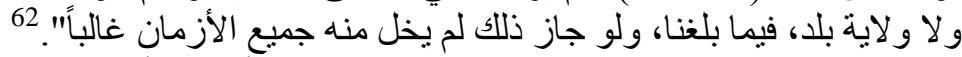

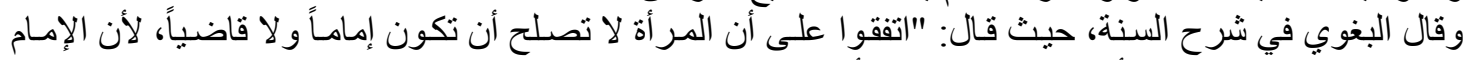

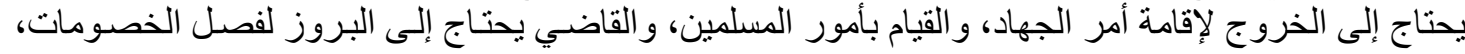




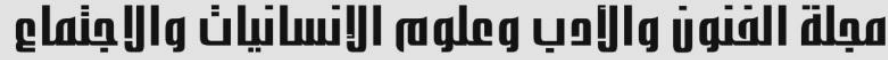 \\ Journal of Arts, Literature, Humanities and Social Sciences} www.jalhss.com

$=$

\section{(1)}

Volume (51) Abril 2020

العدد (51) ابريل 2020

و المر أة عورة لا تصلح للبروز، وتعجز لضعفها عند القبام بأكثر الأمور ، و لأن المر اة ناقصـة، و الإمامـة و القضـاء من كمال الو لايات، فلا يصلح لها للإوز إلا الكامل من الرجال".

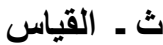

لا يجوز ممارسة القضاء للمبر أة لأنهم قاسوا:

أولاً: على الإمامة العظمي قال ابن قدامة(ت 620هـ ) - رحمه اله -: "و لأنها لا تصلح للأمامـة العظمى و لا لتولية

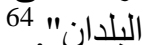
وقال ابن رشد: (ت595هـ) - رحمه الله -: "فمن رد قضاء المر أة شبهه بالإمامة الكبرى".

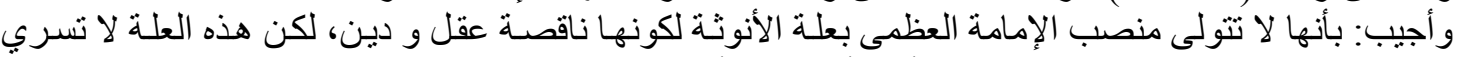

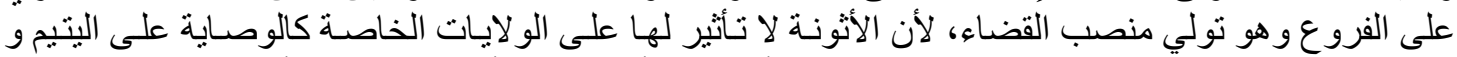

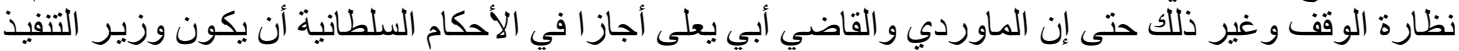

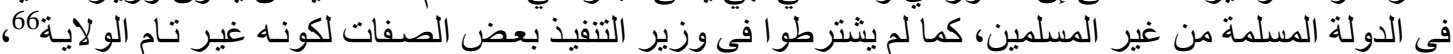

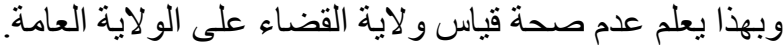

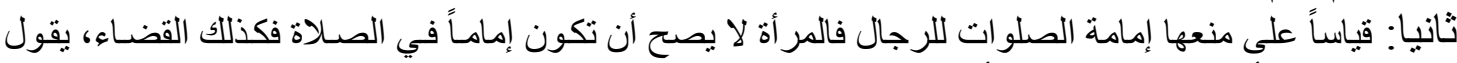

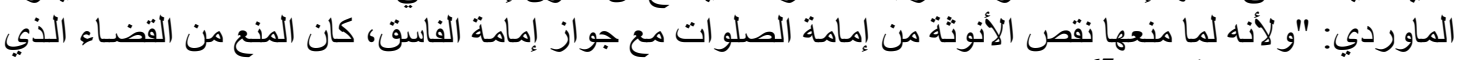
لا بصح من الفاسق أولى".

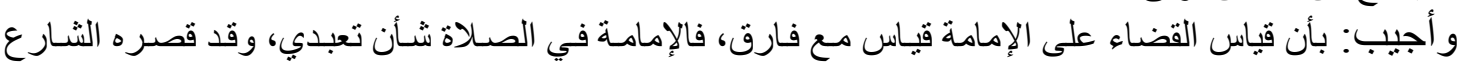

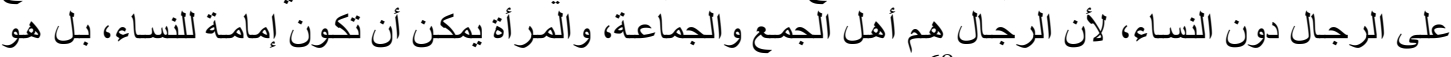

مستحب عند فقهاء الثافعية ، و الحنابلة. 68

ج - المعقول

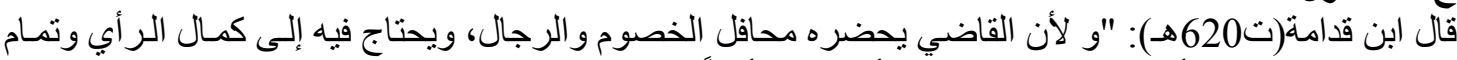

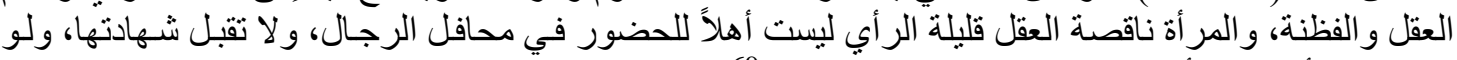

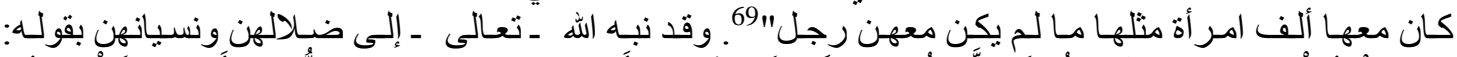

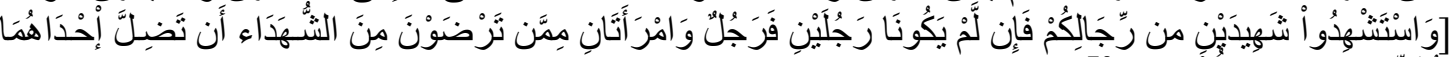

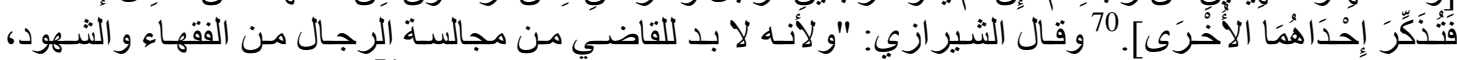

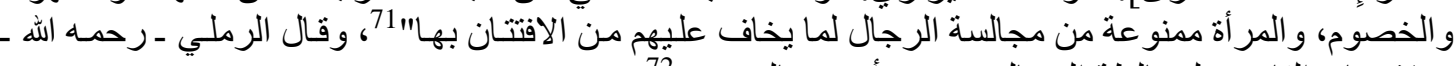

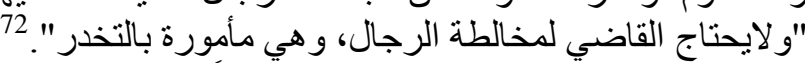

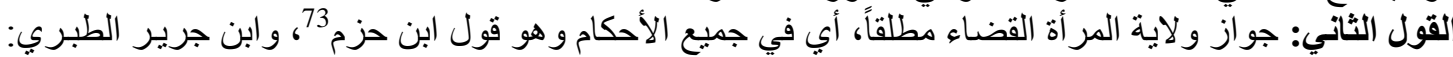

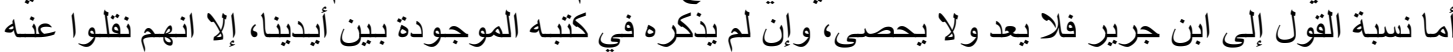
في كثبر من النصوص الف من ذلانك:

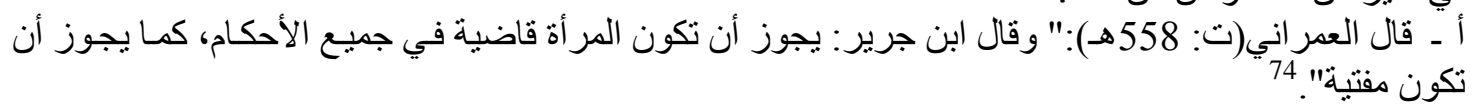

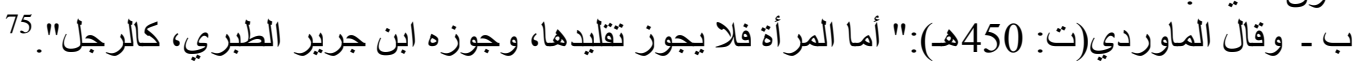

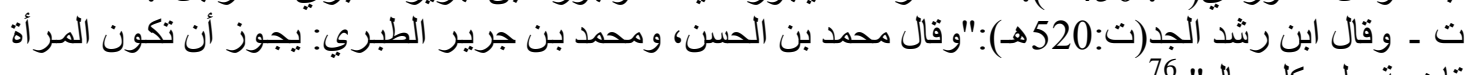

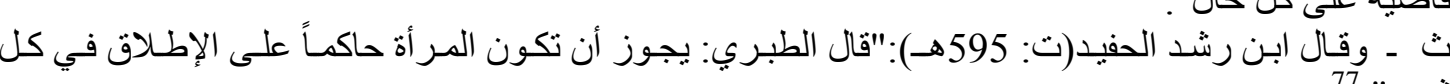
ج - وكيء انقله ابن الجزي (ت 741 هـ)، فقال:"و أجاز أبو حنيفة قضاء المر أة في الأمو ال و أجازه الطبري مطلقاً. 78

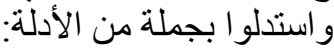

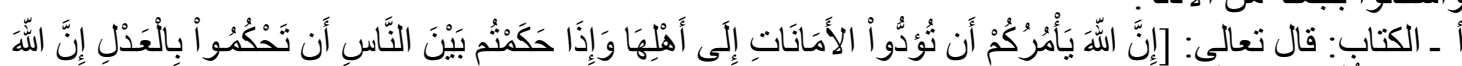

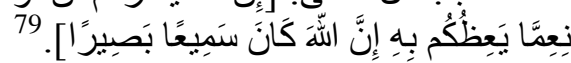

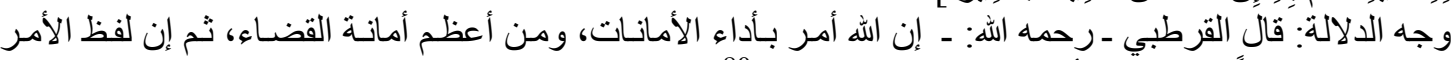
و الحكم جاء عاماً فيشمل الكر أة و الرجل على على حد سواء. 80 


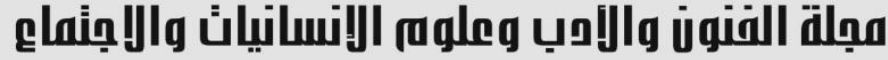

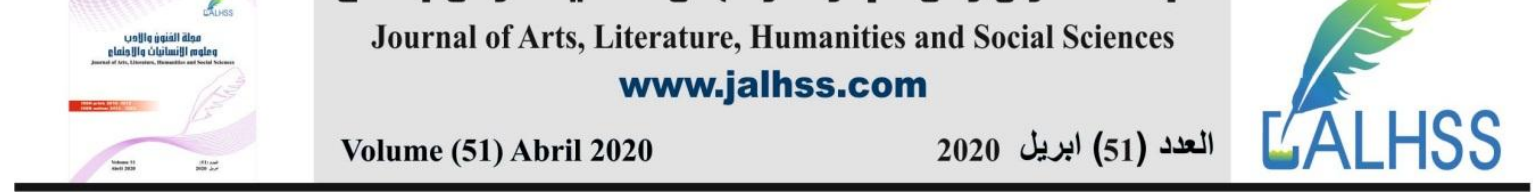

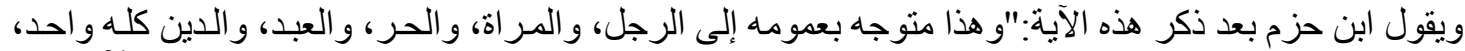

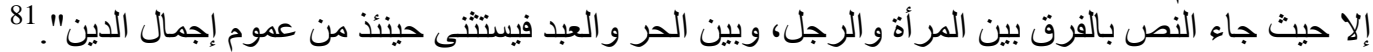

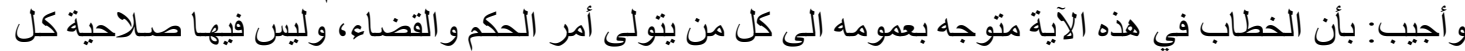

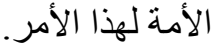

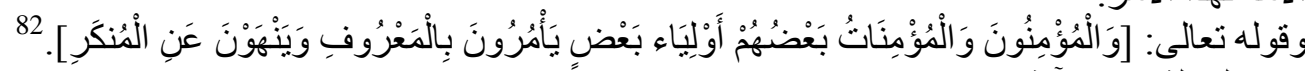
وجه الدالة: هذه الآية فيها مبدواندان:

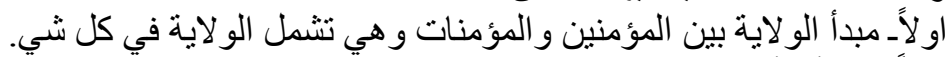

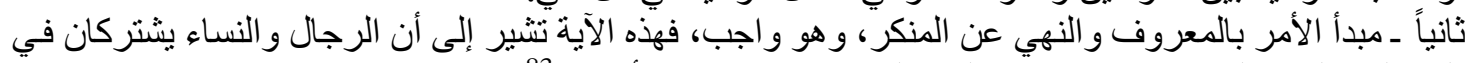

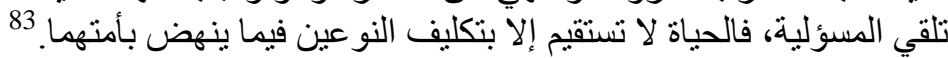

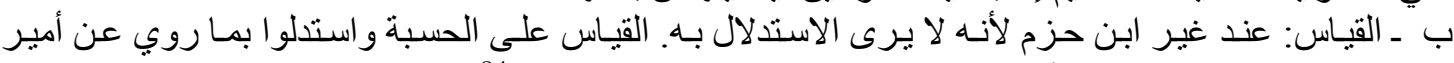

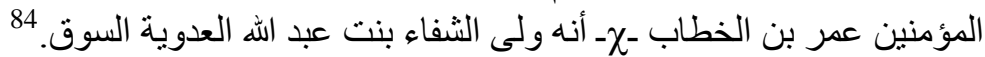
وأجيب: بأن الخبر لم يثبت، فقد ساقة ابن حزم ـ رحمه الله ـ غير مسند بصيغة التمريض، التي تدل على على الضعف

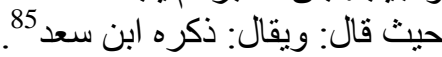

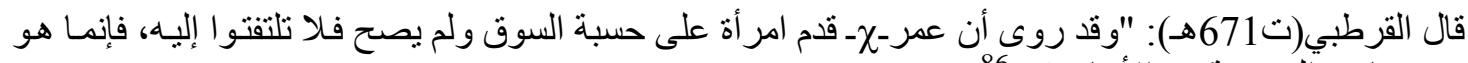

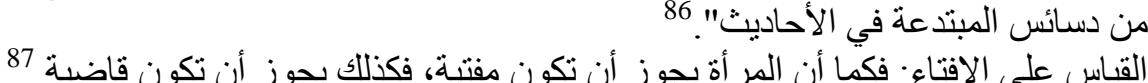

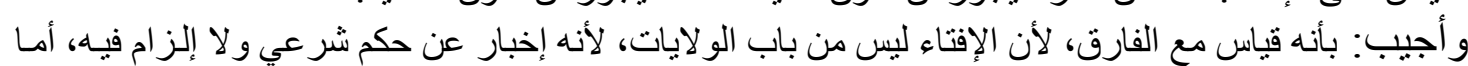

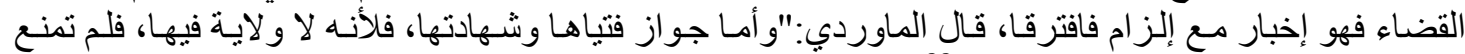

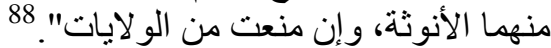

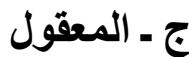

إن الأصل في الأشياء الإباحة ما لم يقم دليل المنع، لذا أن كل من يأتي منـه الفصل بين النـاس فحكمه جائز إلا مـا خصصة الإجماع من الولاية الكبرى.

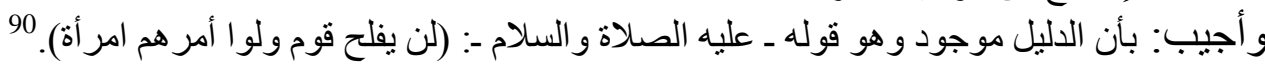

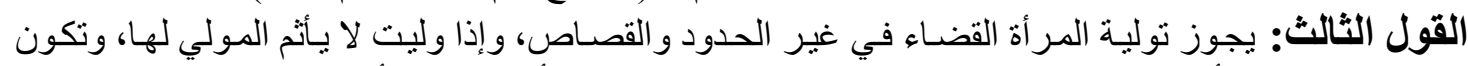

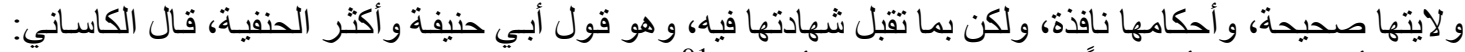

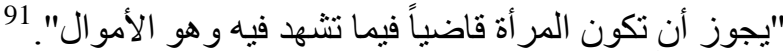

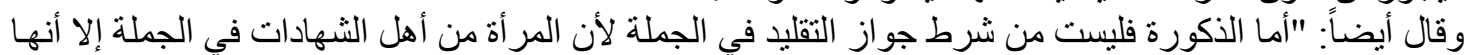

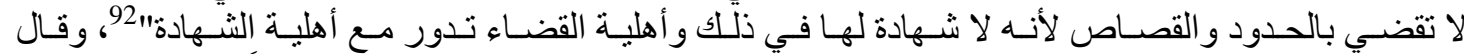

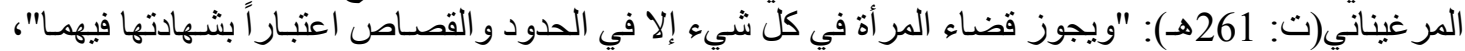

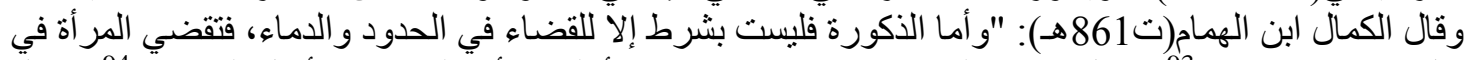

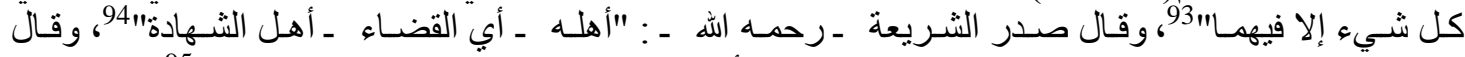

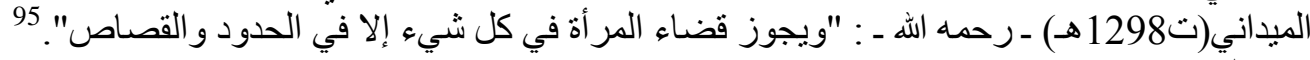

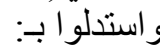
أ ـ القياس على الثهادة: المر أة أهل للشهادة في غير الحدود و القصـاص، كمـا ثبت بـالنص، ويجوز لها أن تقضي

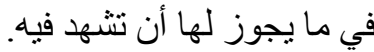
قال أبو حنيفة: "يجوز أن تكون قاضية في في غير الحئ الحدود لأنه لا يجدر أن تكون شاهدة فيه، ويجوز قضاء المر أة في

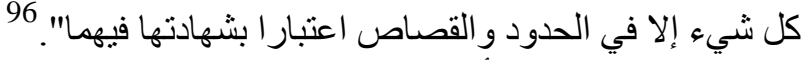

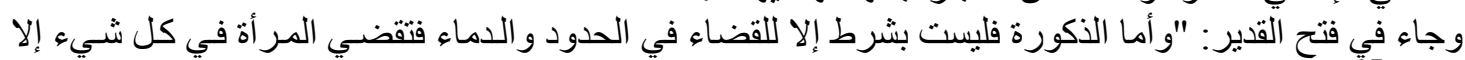

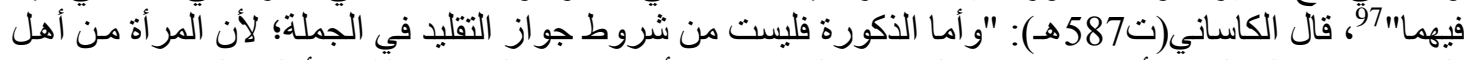

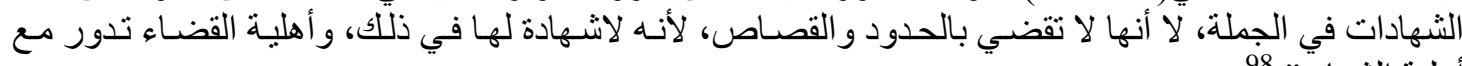

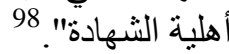
يتبين أنهم قاسوا جواز نولي المر أة القضاء على جواز الثهادة لها في كل شيء عدا الحدود و القصاص. 


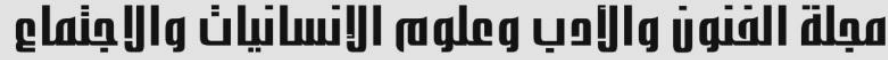

\author{
Journal of Arts, Literature, Humanities and Social Sciences \\ www.jalhss.com \\ Volume (51) Abril 2020 \\ العدد (51) ابريل 2020
}

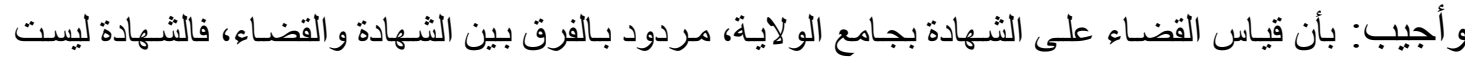

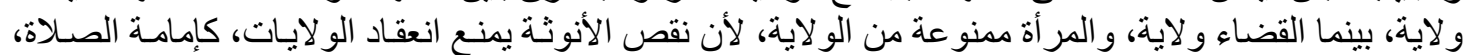

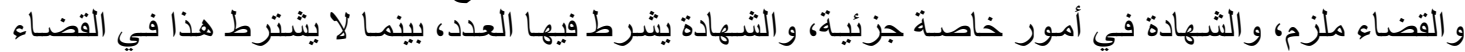

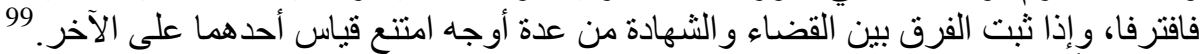

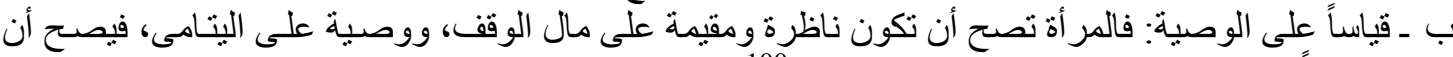

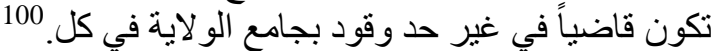

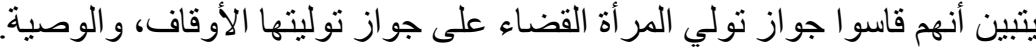

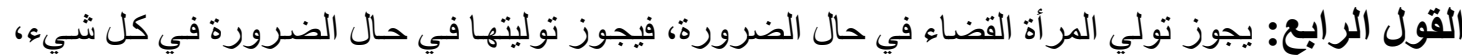

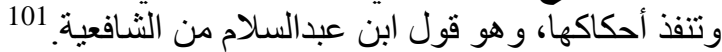

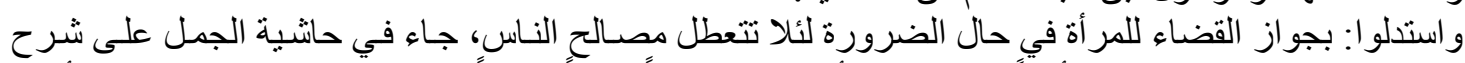

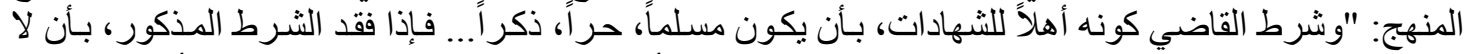

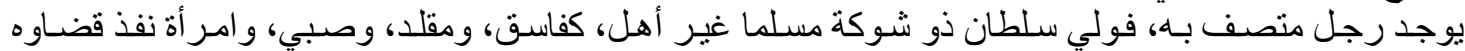

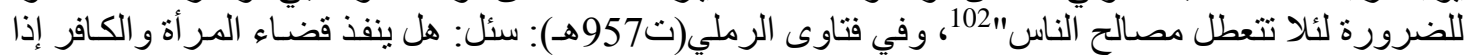

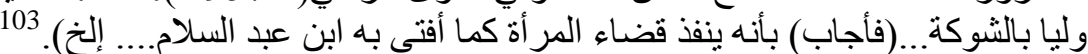

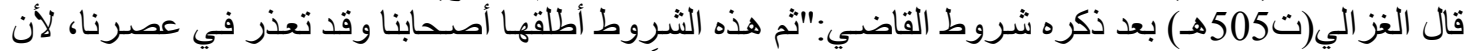

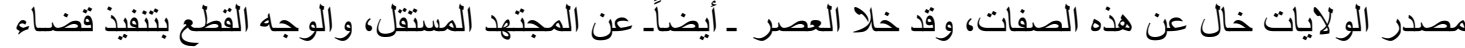

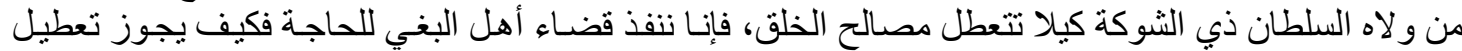

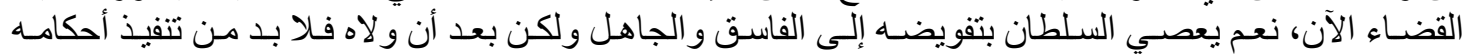

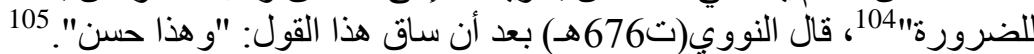

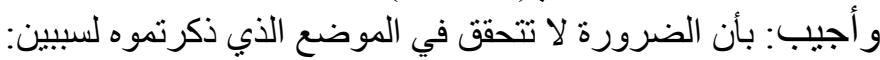

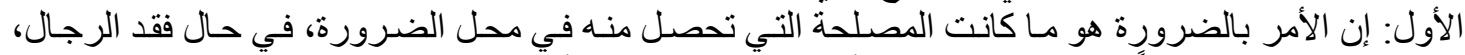

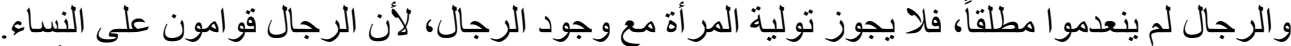

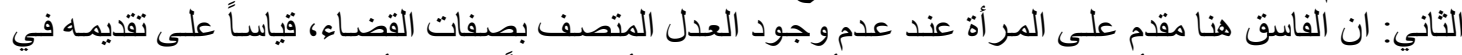

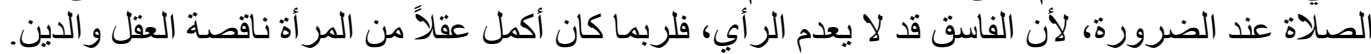

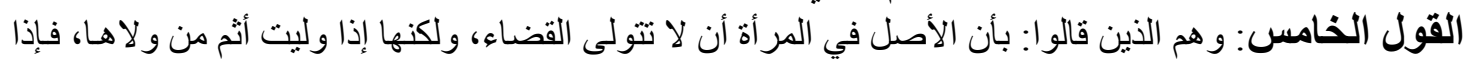

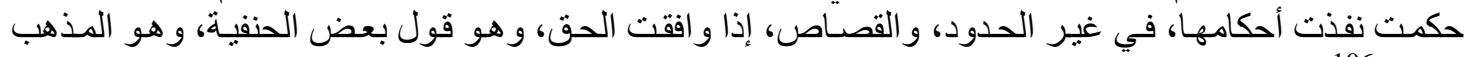

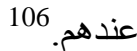

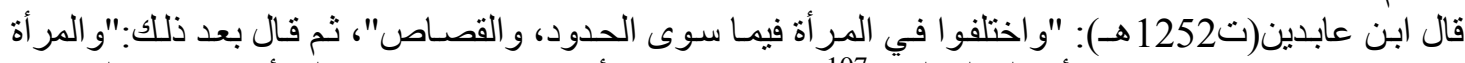

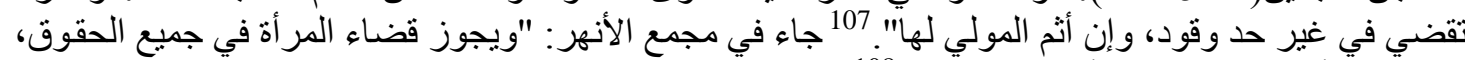

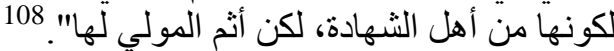

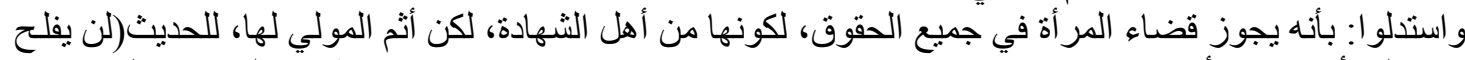

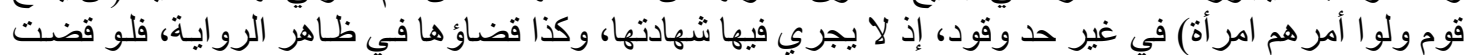

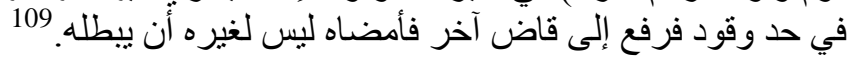

الراجح

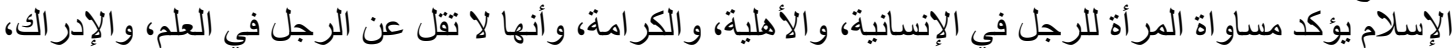

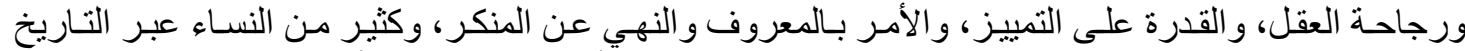

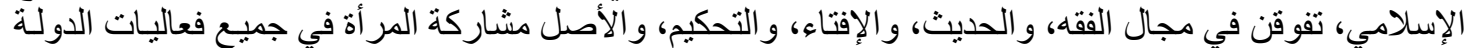
و وعليها توفير الظروف المئ الملائمة لها.

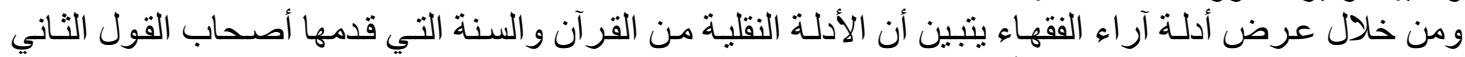

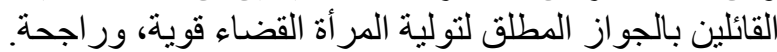

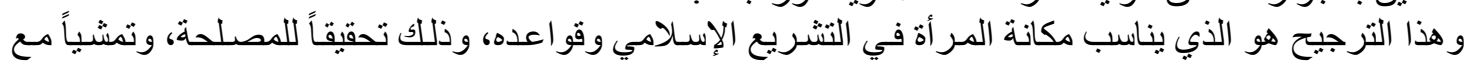

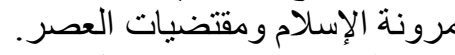
وهذا الترجيح يتبين من خلال عرض الأنط النقاط: 


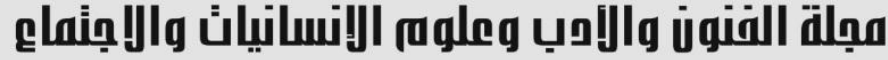

\author{
Journal of Arts, Literature, Humanities and Social Sciences \\ www.jalhss.com \\ Volume (51) Abril 2020 \\ العدد (51) ابريل 2020
}

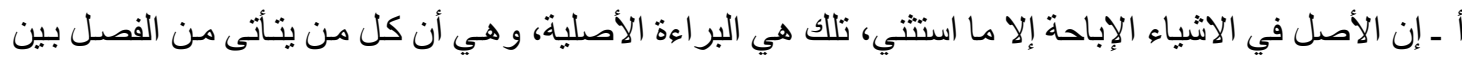

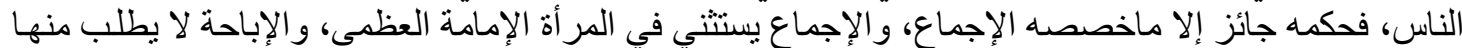

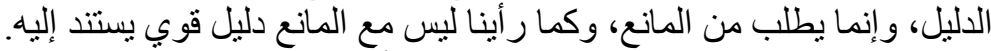

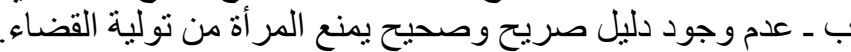

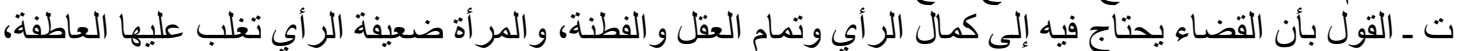

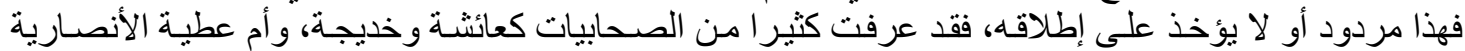

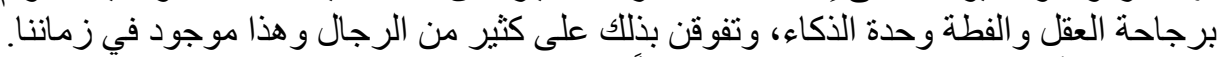

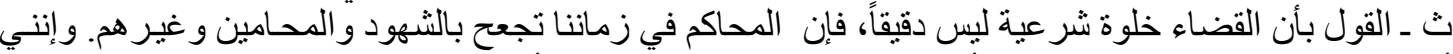

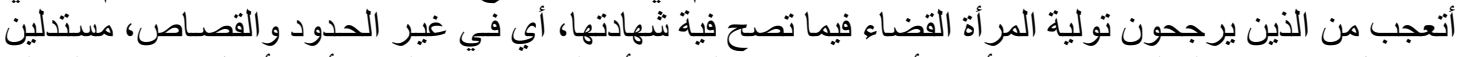

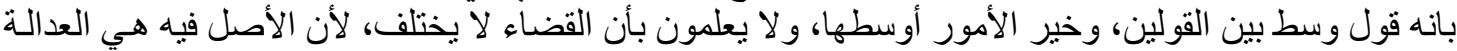

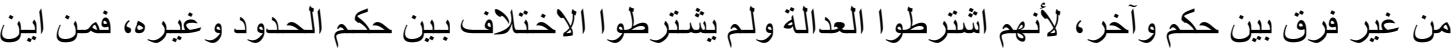

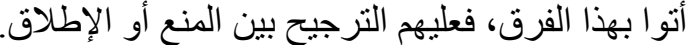

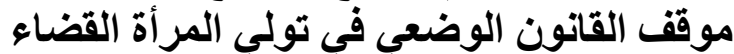

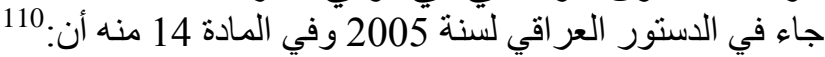

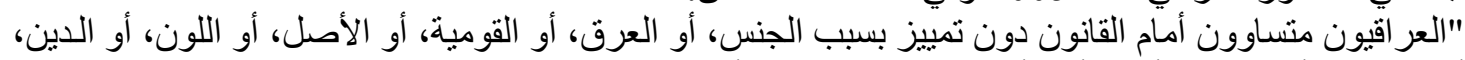

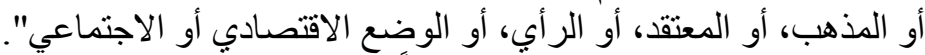

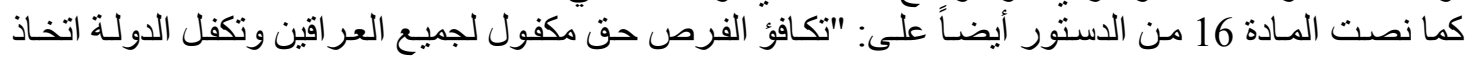

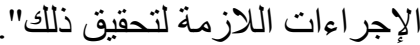

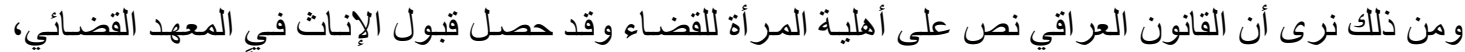

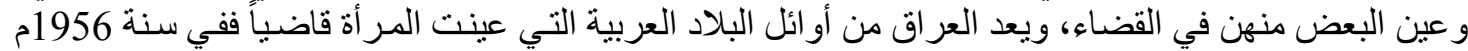

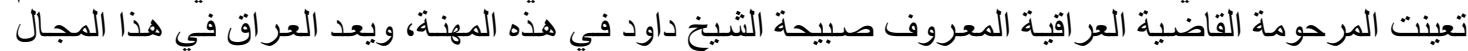

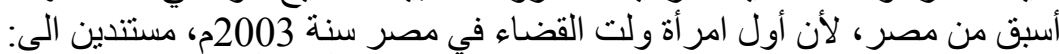

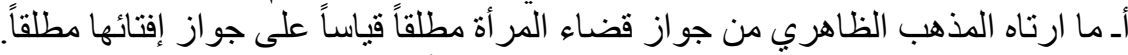

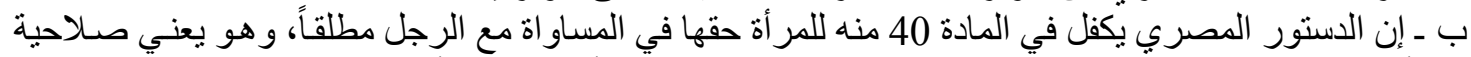
المر أة للعمل في كافة الوظائف و المجالات التي يعمل فيها الرجل، و أنه لا يصح أن تقتصر وظائف معينة كالقضاء مثلاً على الرجآل فقط دون النس النساء.

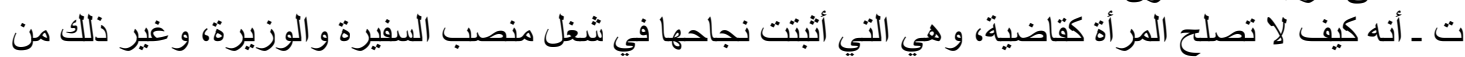

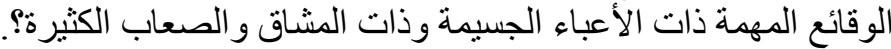

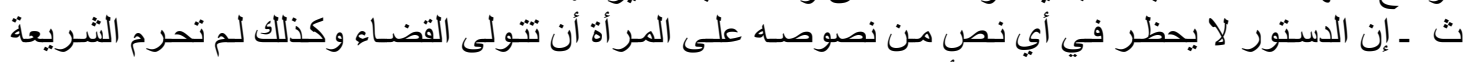

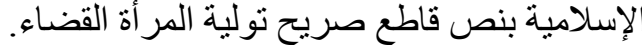

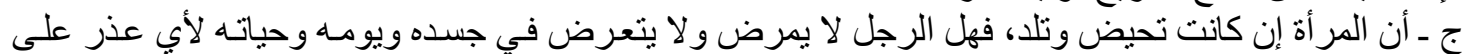
الإطلاق يحول بينه وبين أدائه لعمله؟ النه

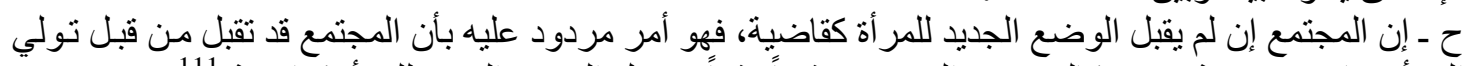

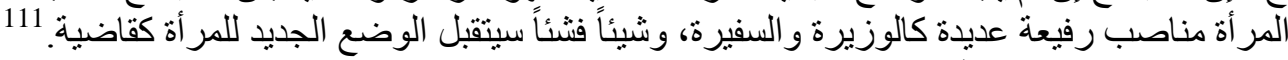

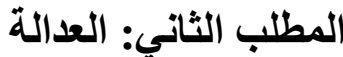
العدالة شرط مهم من شروط القضاء، ويقصد بها الإمتناع عن الكبائر ، و عدم الإصـر ار على الصنغائر و الترفع عما يقدح في المرو ءة، ولذلك لـا لا يولى الحكم فاقده، أب الفاسق.

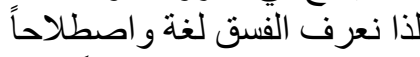
الفسق لغة واصطلاحاً:

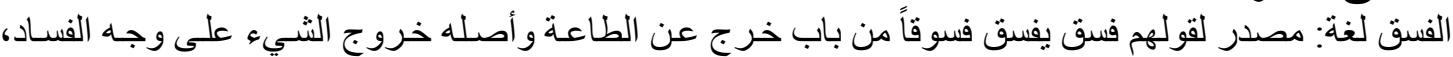

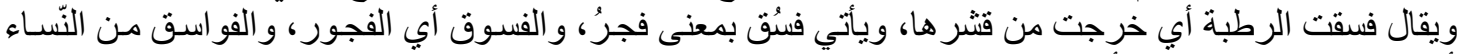

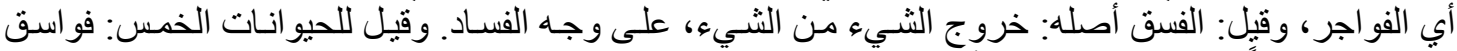

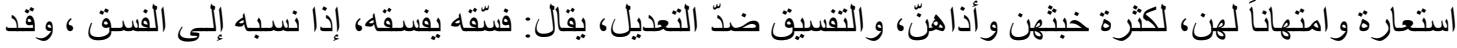




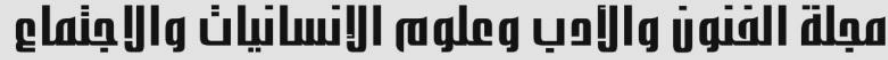

Journal of Arts, Literature, Humanities and Social Sciences
www.jalhss.com

يكون الفسق بمعنى الثرك والإثم. 112

الفسق اصطلاحاً:

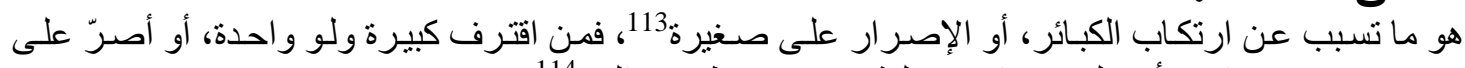

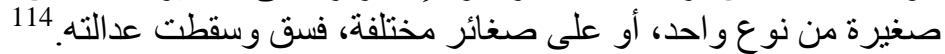

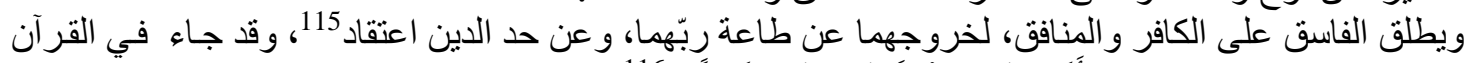

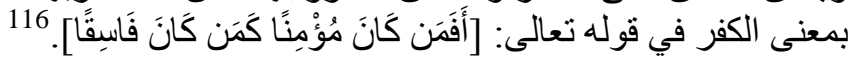

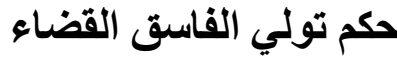

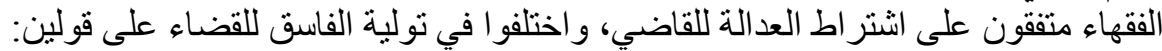

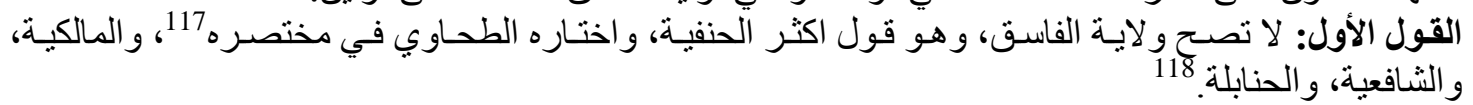
القول الثاني: تصح ولاية الإنة الفاسق، وهو مذهب الحنفية، ورواية عند الحنابلة. 119

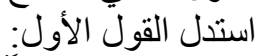

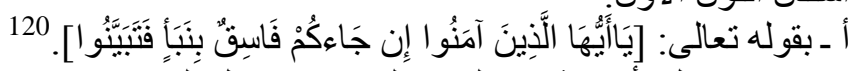

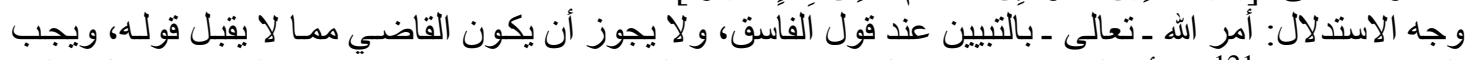

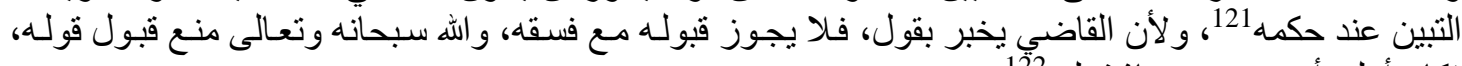

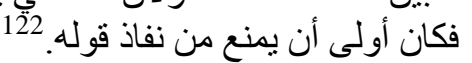

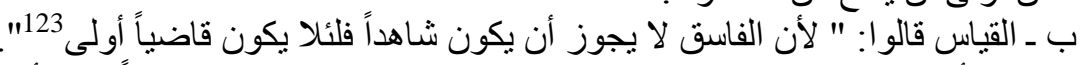

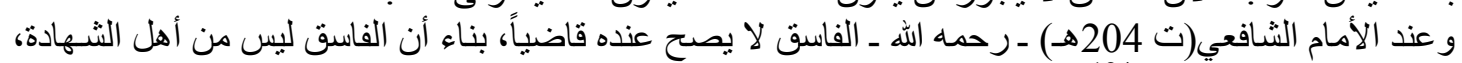
فلا يكون من أهل القضاء.

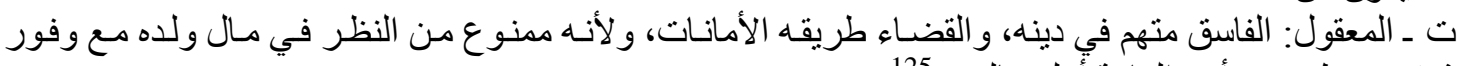

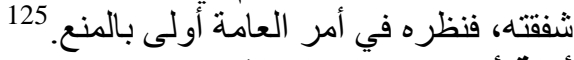
أدلة أصحاب ألقول الثاني: ألثان

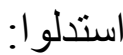
أ ـ بحديث رسول الله ـ صلي اله عليه وسلم -: ( إنه سيكون عليكم أمر اء يؤخرون الصـلاة عن أوقاتها، ويخنقونها

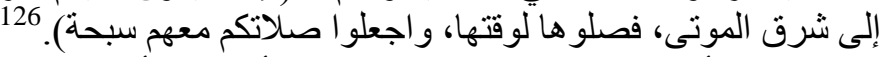

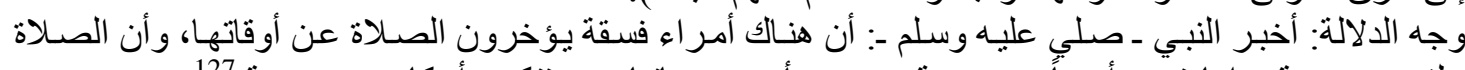

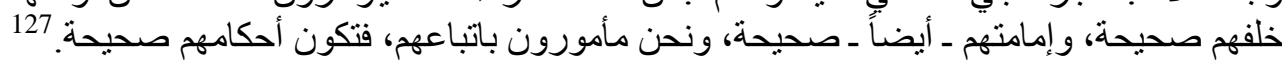

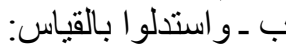

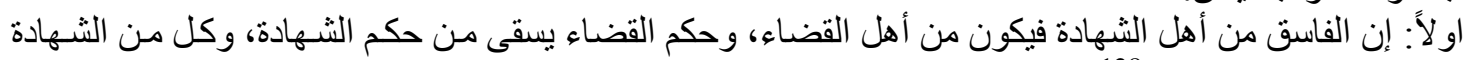
و القضاء من باب الو لاية. الفية.

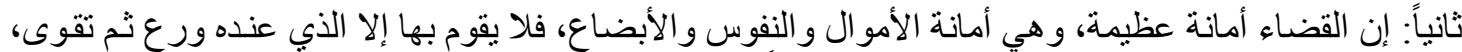

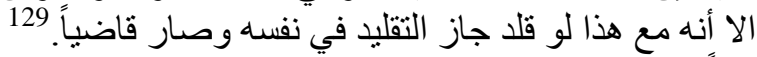

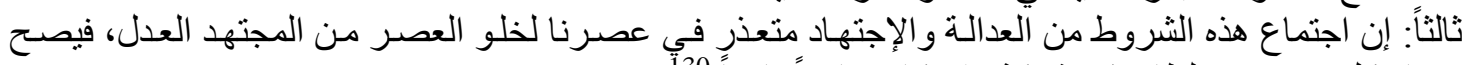

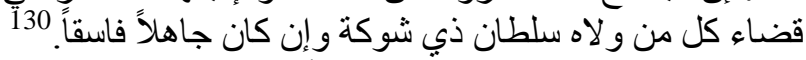

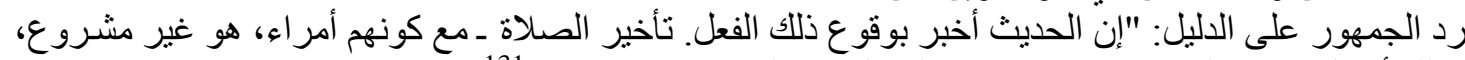

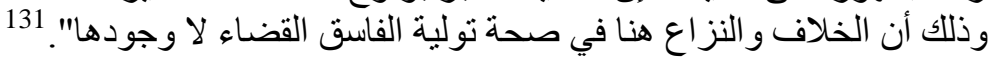

الراجح

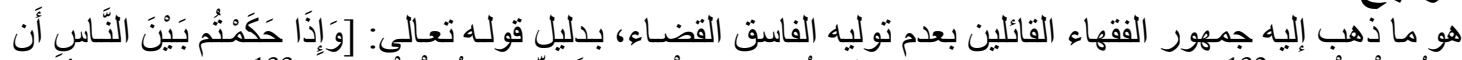

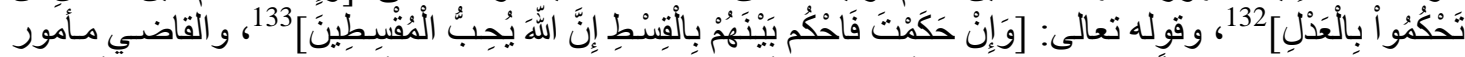

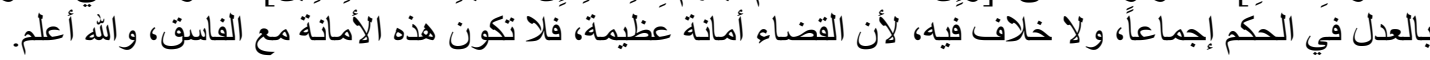




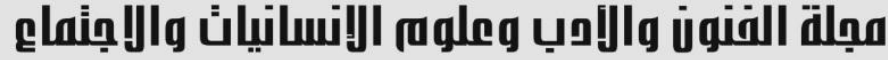

Journal of Arts, Literature, Humanities and Social Sciences
www.jalhss.com
$=\quad$ Volume (51) Abril 2020

جاء في القانون المصري: "أنه يشترط فيمن يعين على منصب القاضي"أن يكون محمود السبرة، وحسن السمعة

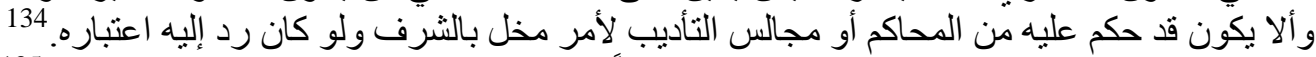

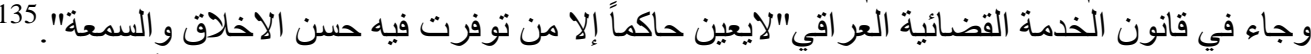

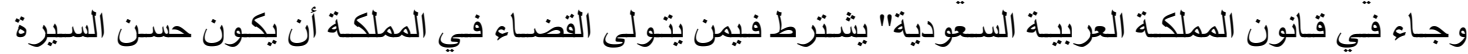

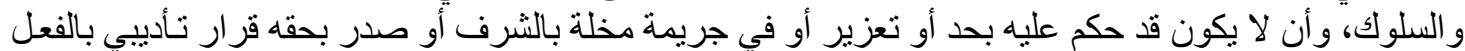
من وظيفة عامة ولو كان قان قد رد إليه اعتباره". 136

المطلب الثالث: الإجتهاد

المقصود بالإجنهاد هو الإئهون يكون الحاكم مقلدا لغيره من الأحكام، فنعرف التقليد لغة واصطلاحاً: مأخذذ من القلادة: ما جعل في العنق يكون للانسان، و الفرس و الكلب و البدنة التي تهدي نحو ها. 137

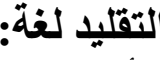
التقليا اصطلاحاً:

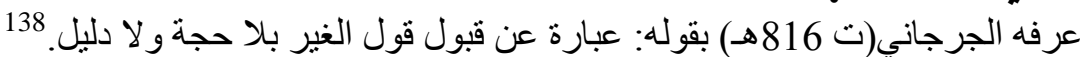

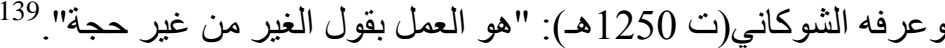

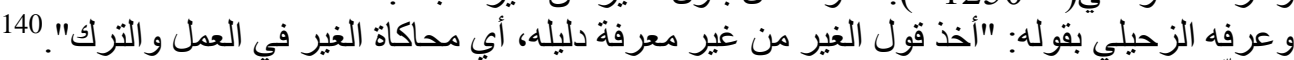

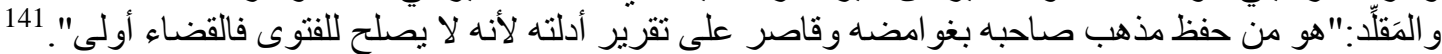

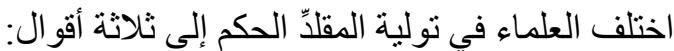

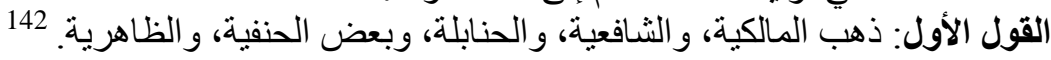

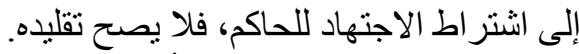

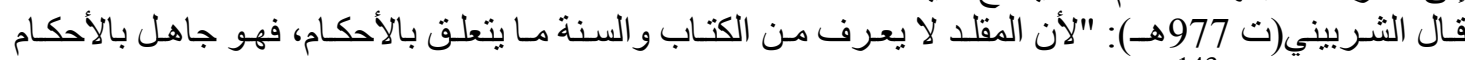
الثريعة فلا يولى".

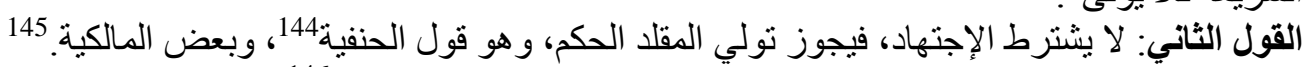

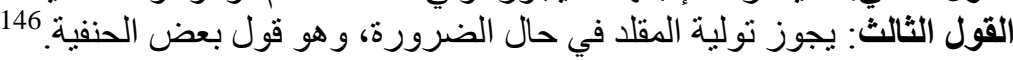

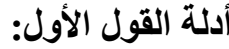
أـ الكتاب الكول

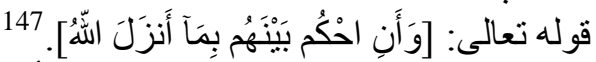

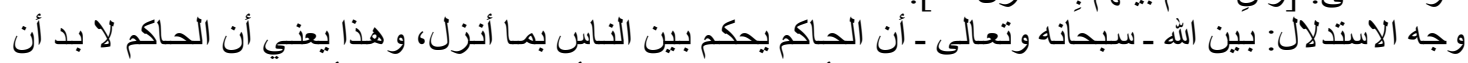

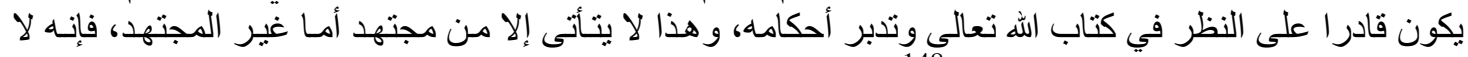

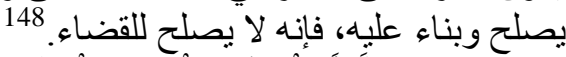

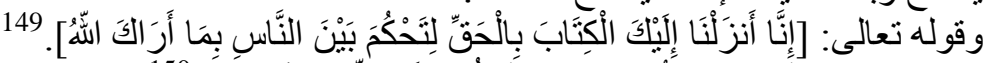

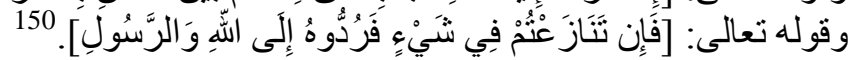
وجان الاستدلال

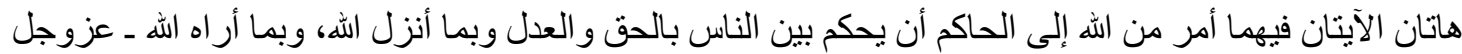

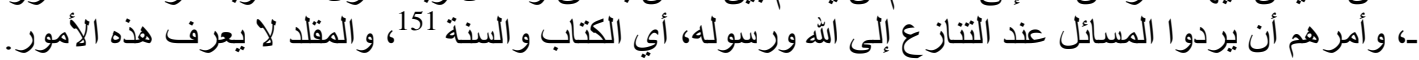
ب ـ ـ السنة

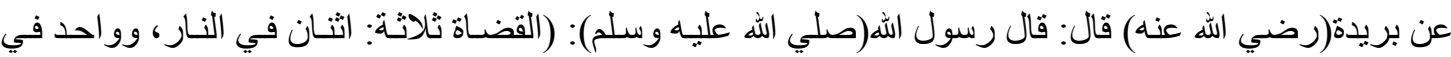

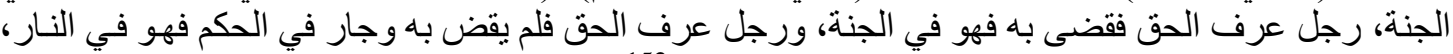
ورجل لم يعرف الحق فقضى للناس على بلى فهل فهو في النهار ).

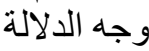

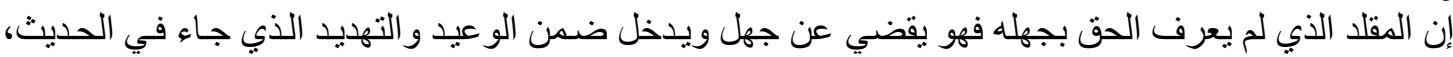

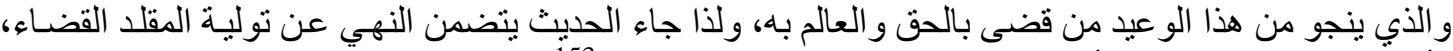

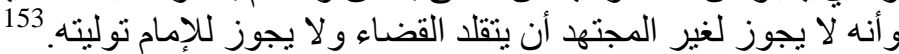
ادلة القول الثاني: استدلو ا بالسنة و المعقول النيل 


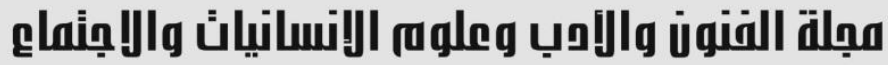

Journal of Arts, Literature, Humanities and Social Sciences
www.jalhss.com

عن علي(رضي الله عنه)قال: "أنفذني رسول الله(صلي عليه وسلم) إلى اليمن و أنا حديث السن فقلت: تنفذني إلى وإلى

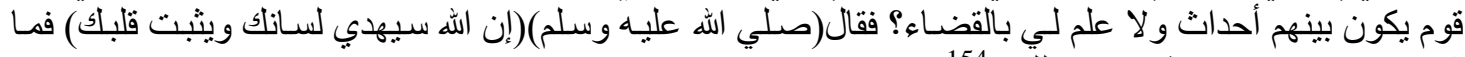
شككت في قضاء بين اثثين بعد ذلك" لأل 154

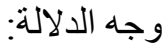

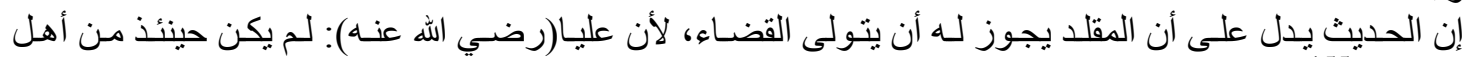

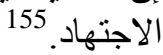

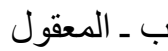

إن المقصود من القضاء هو إيصال الحق الى مستحقه، و إن هذا يحصل من القاضي المقلد، الذي يمكنه أن يقضـي

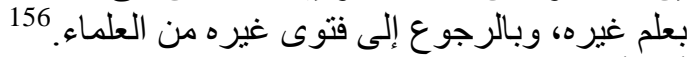

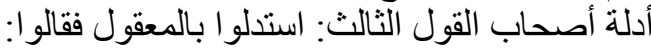

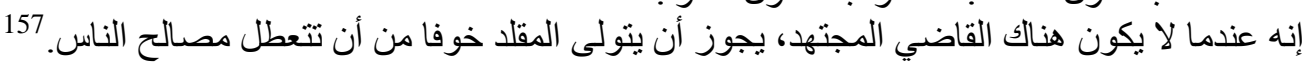

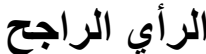

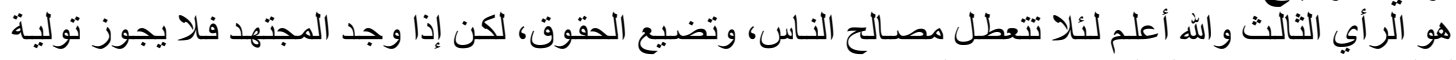

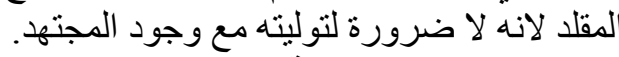

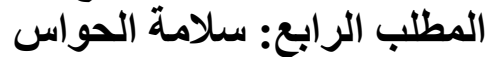
المقصود بـالحواس في الفقه الإسـامي هي، البصدر، و والسمع، و الكـلام، و الفقهاء متفقون على منع تولي الحساكم

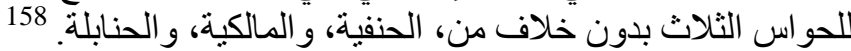

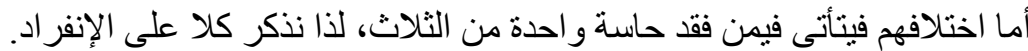

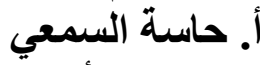

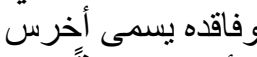

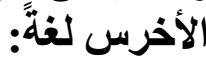

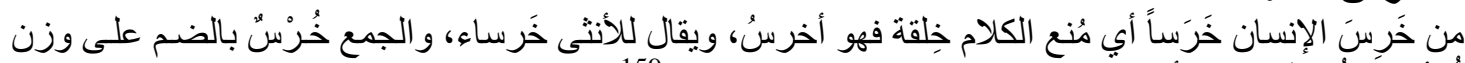

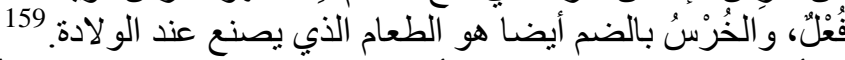

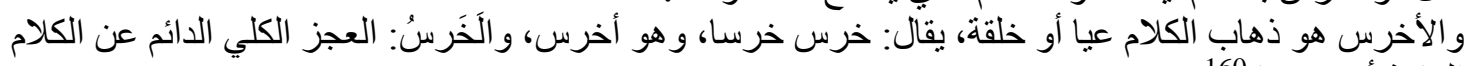
العاهة أو غير ها.

$$
\begin{aligned}
& \text { الأخرس في الاصطلاح: }
\end{aligned}
$$

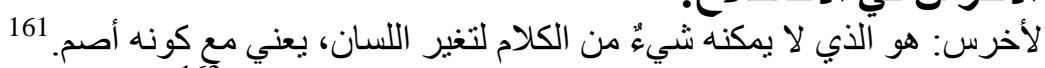

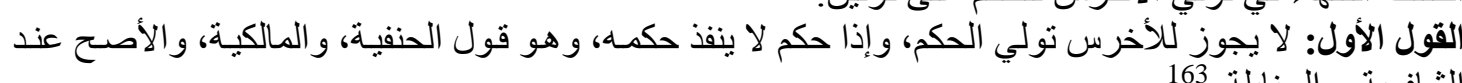
الشافعية، و الحنابلة. 163

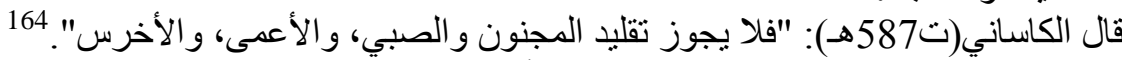

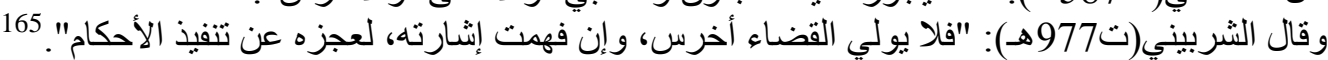

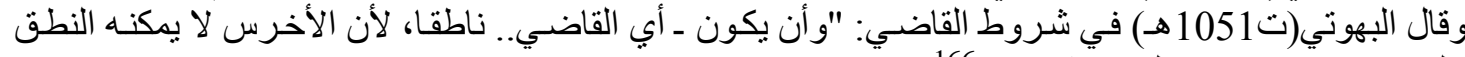
بالحكم، و لا يفهم جميع الناس إنشارته".

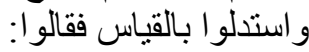

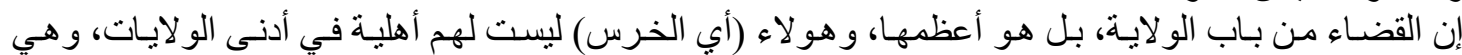

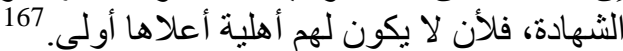

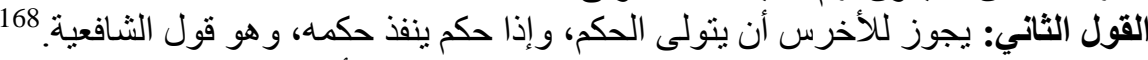

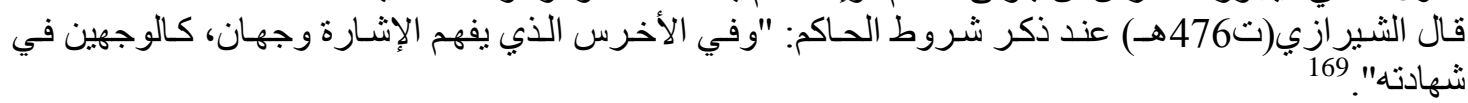




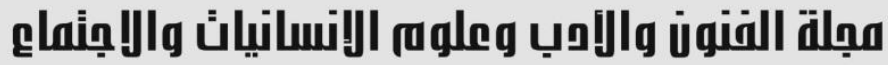

Journal of Arts, Literature, Humanities and Social Sciences
www.jalhss.com

(الراجح

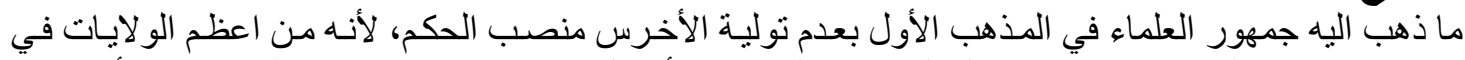

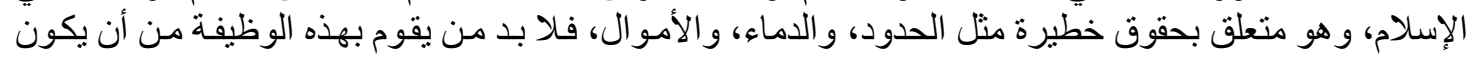

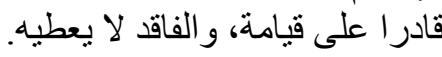

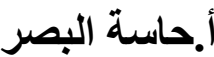

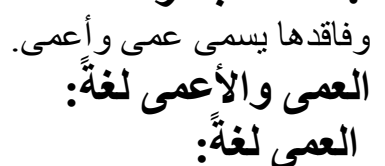

فال ابن فارس(ت 395هـ): عمى العين و الميم و الحرف المعتل أصل و احد يدل على ستر وتغطية من ذلك العمى:

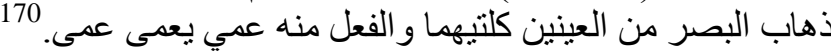
وقال الزبيدي: عمي كرضي عمىى، مقصور ذهب بصني بصره كله، أي من كلتا العينين، و لايقع هذا النعت على الواحدة، الأعمى لغة:ً:

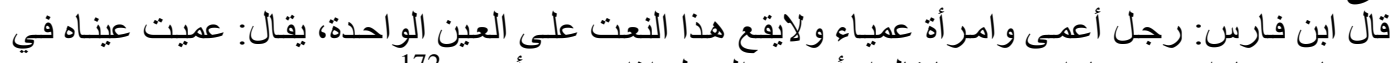

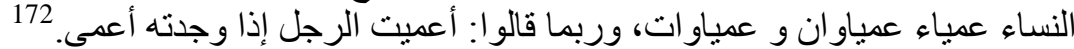

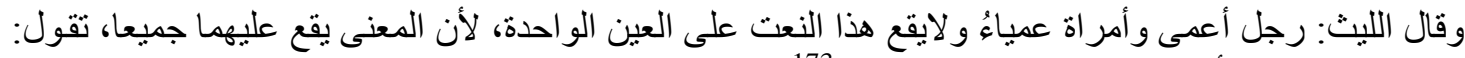

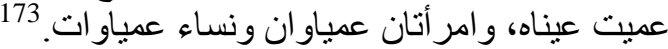

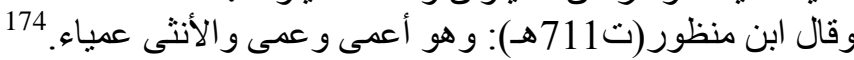

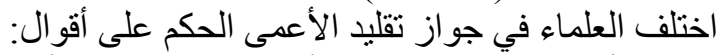

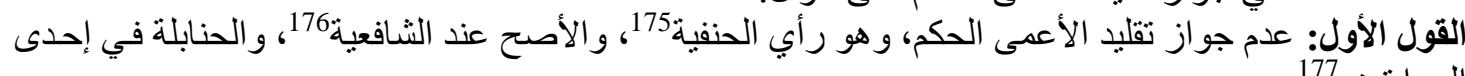

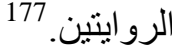
القول الثثاني: ذهب المالكية إلى أن الحواس الثناث السمع، و البصر ، و النطق شرط في ولايـة الحساكم، وليست

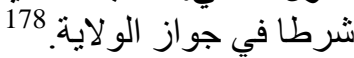

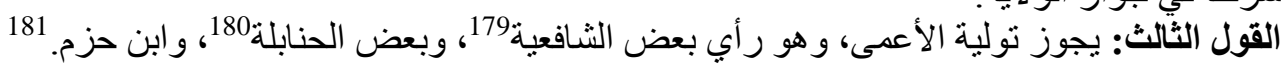

استدلو ا بالمعقول فقالو ال: إن الأعمى ليس أهلا للحكم، لأنـه لا يتمكن من التفرقة بين المدعي و المدعى عليه، و لا يعرف المقر من المقر له. 182

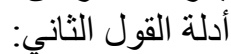

1- أن البصر لو كان شرط جو از لكانت و لاية الأعمى باطلة و أحكامه لاغية غير منعقدة.

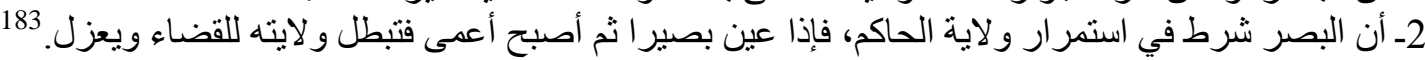

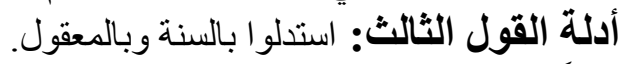

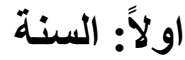

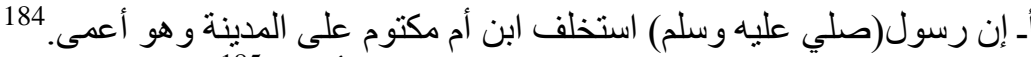

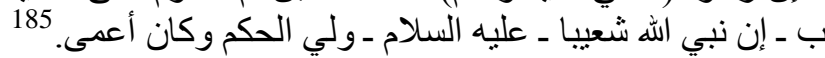

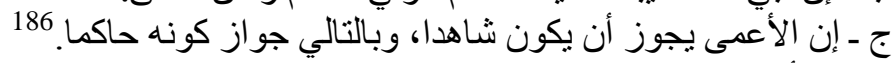
مناقشة أدلة المجيزين: الإني

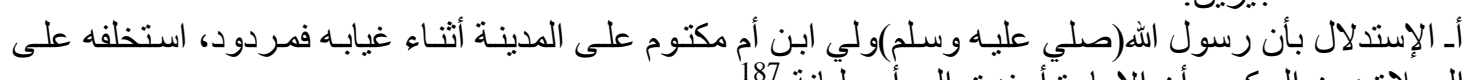

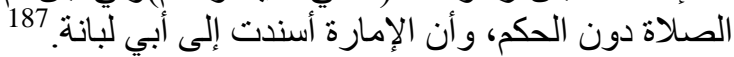

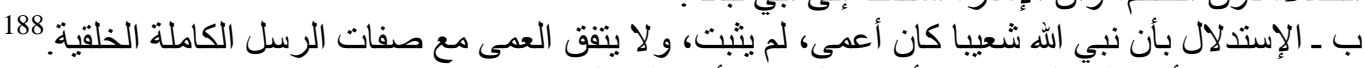

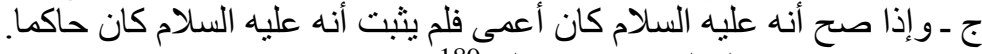

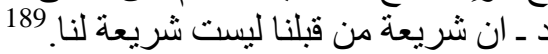




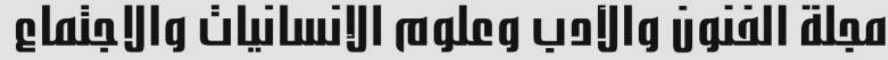

Journal of Arts, Literature, Humanities and Social Sciences
www.jalhss.com
$=\quad$ Volume (51) Abril 2020

الراجح

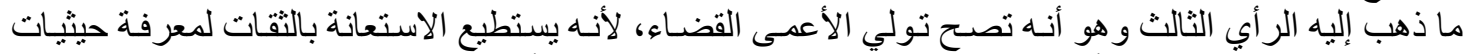

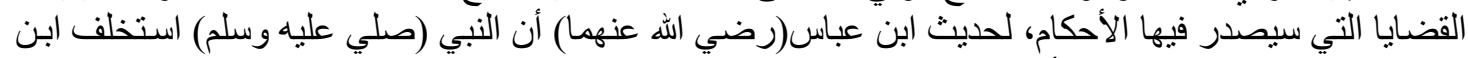
وكتوم على "الصلاة وغير ها من أمر المدينة.

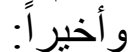

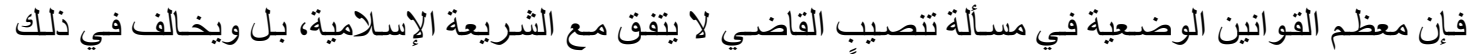

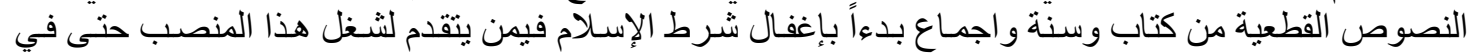

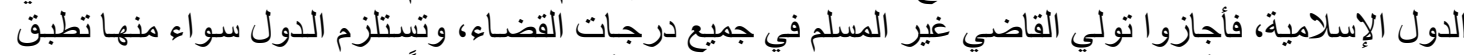

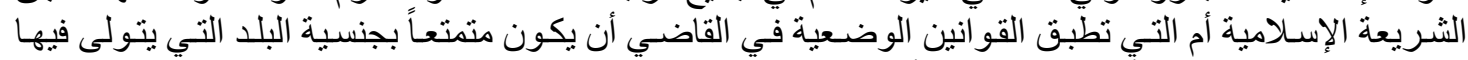

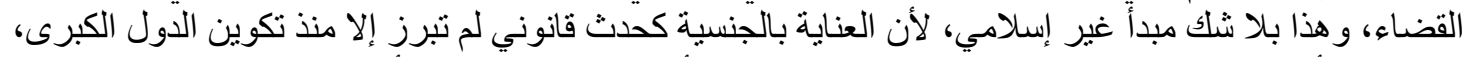

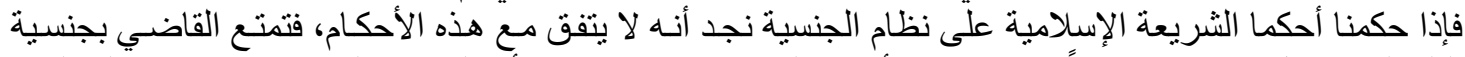

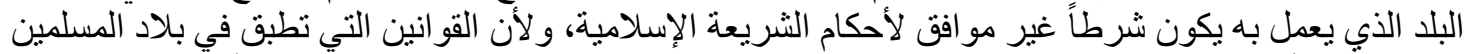

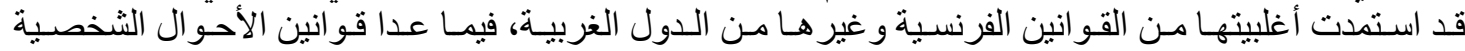

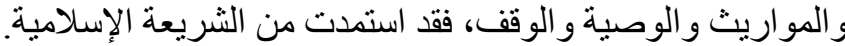

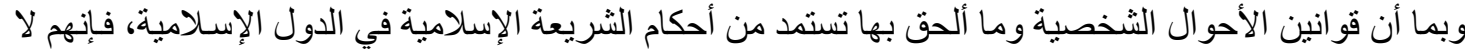

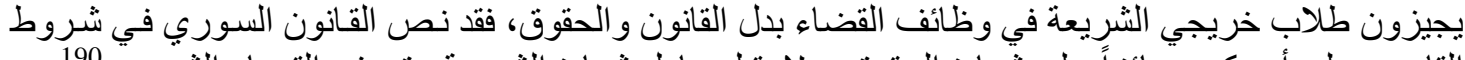

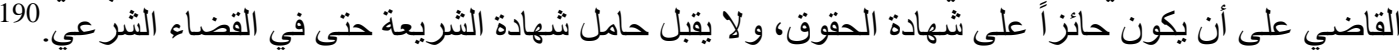

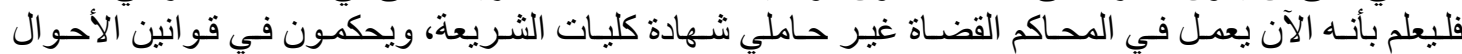

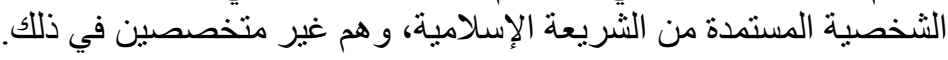

الخاتمة والنتائج

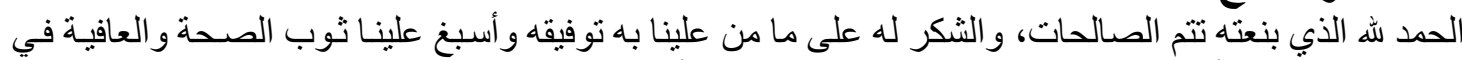

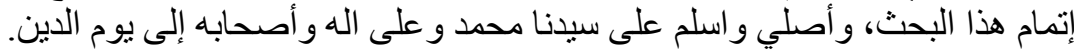

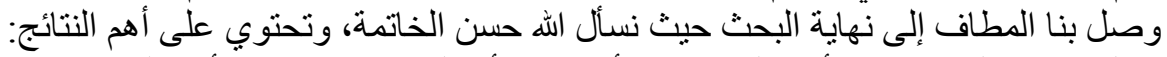

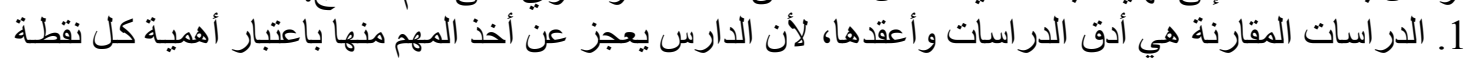
من نقاطها.

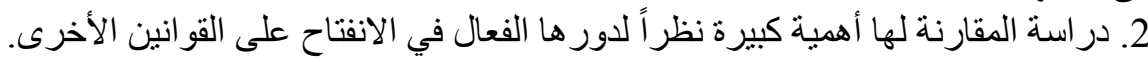

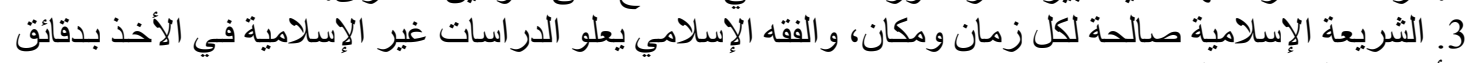
الأمور ، و التنسيق و الترنيب. 4. تعد و لاية القضاء من أهم و أعظم دعائم نظام الحكم في الدولة.

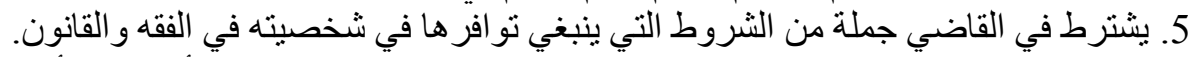
6. تعتبر المحاكم من المر احل الحضارية التي وصنل إليها الإنسان القديم بعد أن كان الفئه الأخذ بالثأر مبدأ لاسترداد

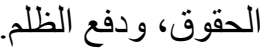
7. من الثروط المختلف عليها الذكورة لكن الر اجح جواز قضـاء المر أة مطلقاً، وهو الر أي السـائد في القوانين الوضعية. 8. يشترط في تنصيب القاضي أن يكون بالغاً في الفقه الإسلامي، خلافاً للقانون الوضعي الذي الذي حدد بالعمر.

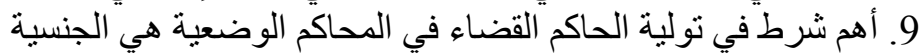

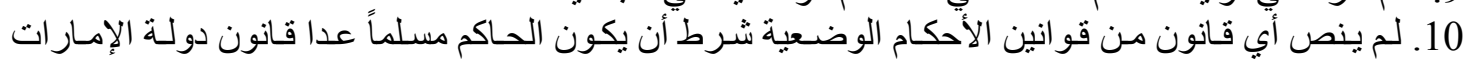
العربية المتحدة.

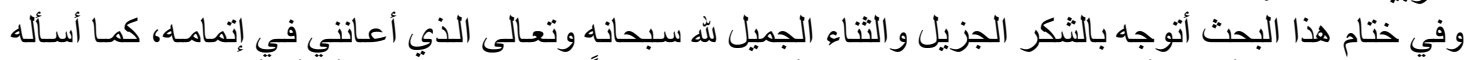

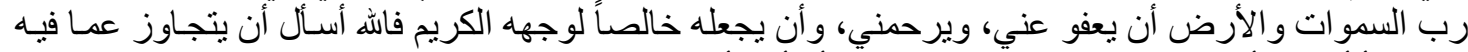

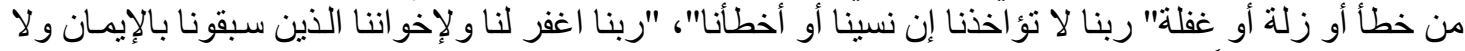

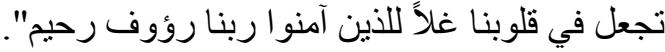




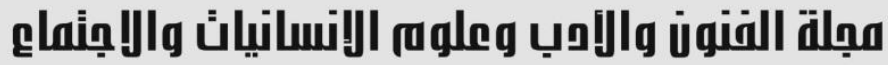

Journal of Arts, Literature, Humanities and Social Sciences www.jalhss.com

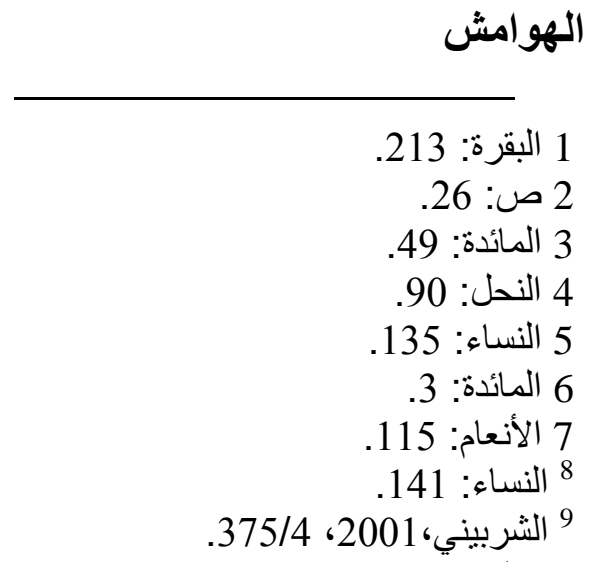

10 الكاساني، 1986، 3/7، ابن رشد، 37/4، 2004، 2004، 243/4، ابن مفلح، 1997، 154/8، 11 11 الشربيني، 2001، 374/4، قليوبي و عميرة، 1995، 2004، 297/4.

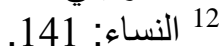
13 الثربيني، 2001، 375/4.

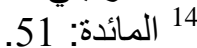
(15 15 16 القرطبي،15 1964، 1986، 1986، 19 17 الكاساني، 1986، 3/7. ابن رشد، 2004، 2004، 243/4، ابن مفلح، 1997، 197/4، 154/8.

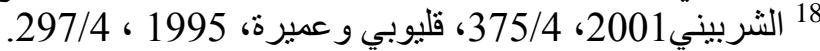

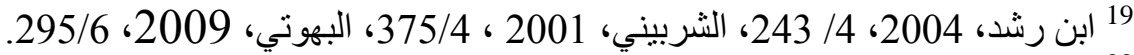

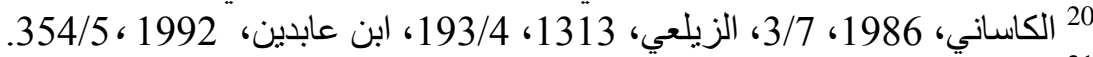

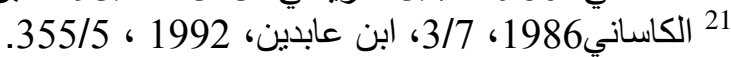
22 ابن رشذ، 2004، 198/، 243، الشربين عابنين، 2001، 2001، 474/4، البهوتي، 2009، 295/6.

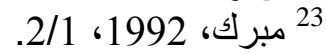

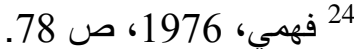
25 قانون الخدمة القضائية رقم(2001) لسنة 1945.

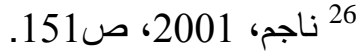
27 الكاساني، 1986، 3/7، الدسوقي، 20010، 2010، 147/4، 474/4، ابن قدامة، 1968 ، 1968 ،

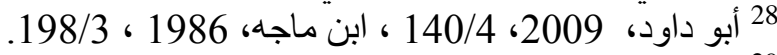

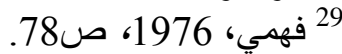
30

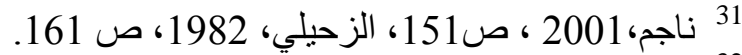

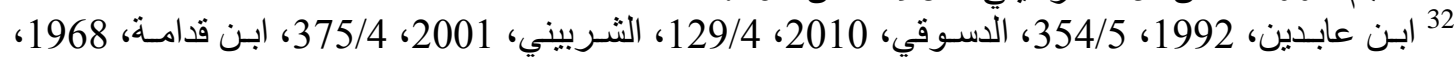




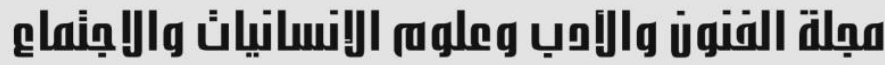

Journal of Arts, Literature, Humanities and Social Sciences

www.jalhss.com

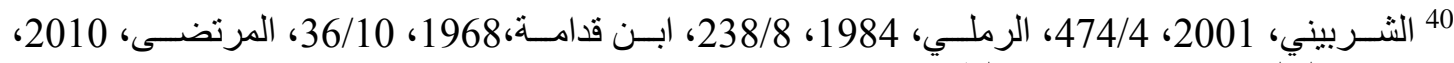
118/6 ، الحلي،2004 ، 238/8، الطوسي، 1387، 1381/2، 101/8.

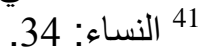

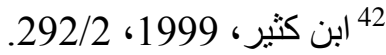

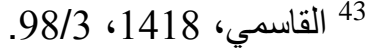

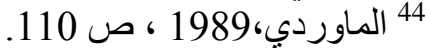
45 القرطبي، 1964، 1422، 161/5.

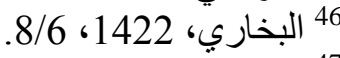
47 النووي، البخاري، 2011، 127/20، 1203، البهوتي، 192/8، 1993، 492/3.

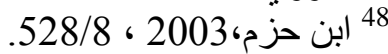
49 ابـو داود، 2009، 299/3، 528/8، الترمــي، 1998، 604، ابـن ماجـه، 1986، 775/2، النسـائي،2001 ، 15

52 الكاساني، 1986، 3/7، الزيلي، 304/8، 1422، 1313، 176/4، الثبيرازي،2018، 378/3، ابن قدامة، 1994، 223/4.

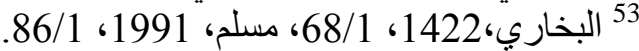

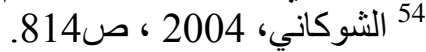

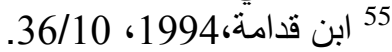
56 عبدالرزاق، 55 57 القر افي، 58 58 الثوكاني، 2004،

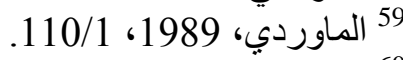

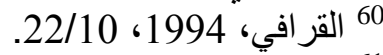

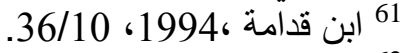

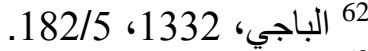

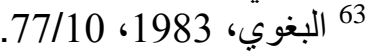

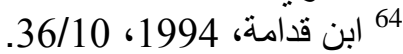

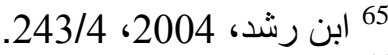

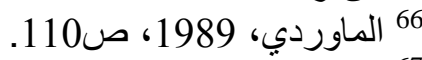

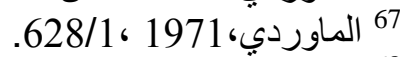

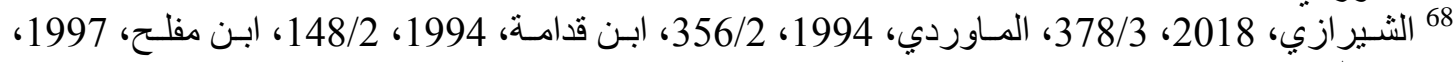

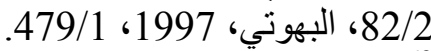
69 ابن قدامة، 1994، 39/9، 39/9. 70 70 البقرة:282.

71 الثيرازي، 2018، 291/2. 72 الرملي، 1984، 2003، 238/8، 73 ابن حزم، 2003، 2000، 527/8.

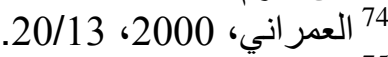

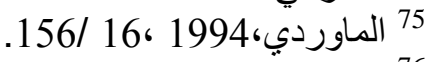
76 ابن رشد، 75

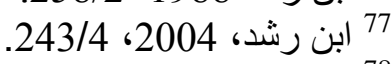
78 ابن الجزي، 2013 ، 2013 ، 195/1، 


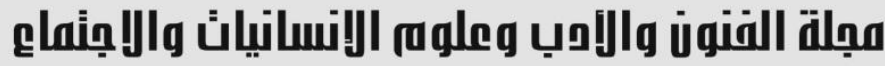

Journal of Arts, Literature, Humanities and Social Sciences www.jalhss.com

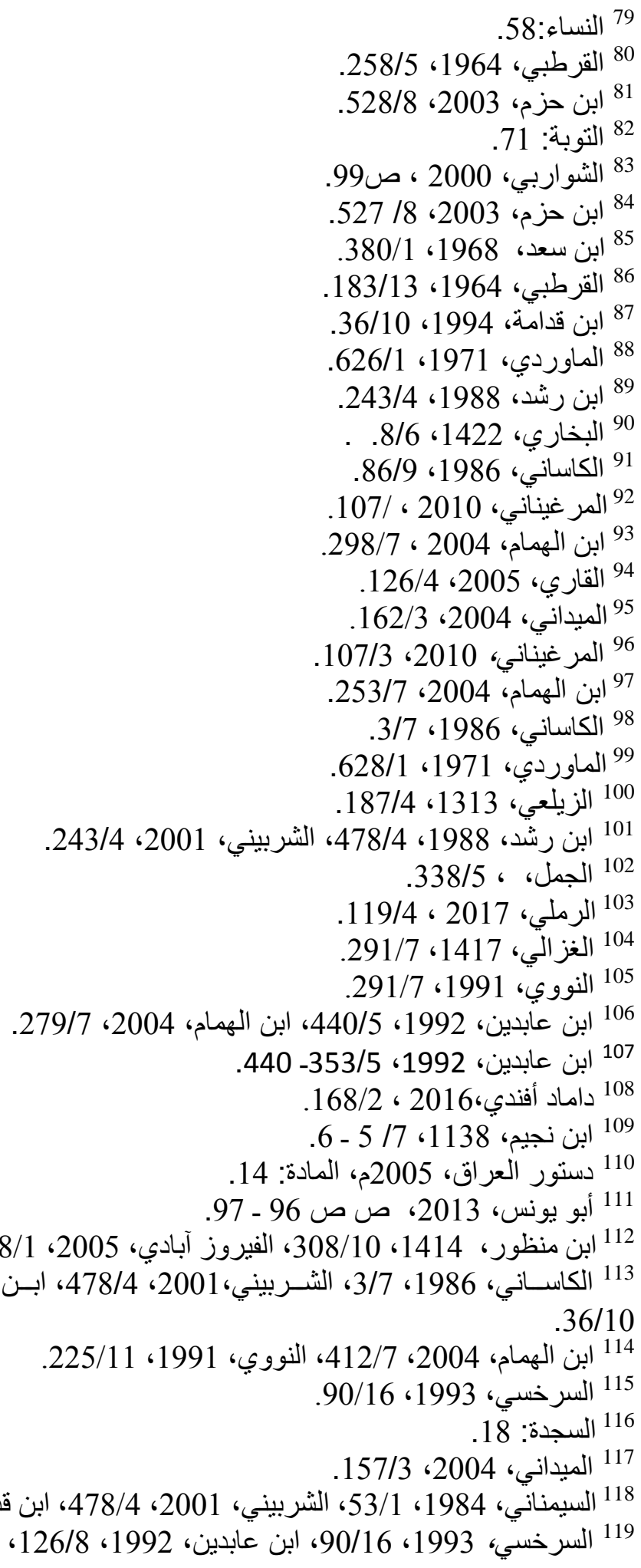




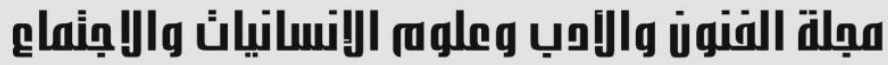

Journal of Arts, Literature, Humanities and Social Sciences

www.jalhss.com

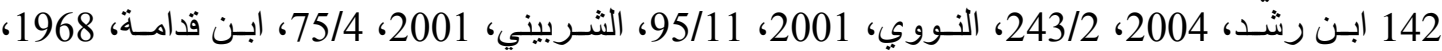
36/10، ابن مفلح، 1997 ، 20/10 2010، السيمناني، 1984، 59/1، 59/2، ابن حزم، 2004، 427/8،

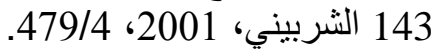
144 الكاساني، 1486، 1986، 3/7، المرنين، 1986، غيناني، 2010، 101/3.

145 ابن فرحون، 1986، 1986، 1986، الكياني، 146 الكاساني، 1486 1986، 3/7، ابن فرحون، 1986، 1986، 20/1.

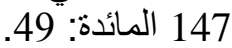
148 ابن قدامة، 1968، 1958، 38/10.

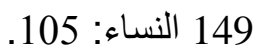
150 151 الثربيني، 2001، 2009، 475/4.

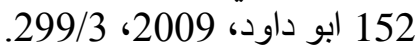

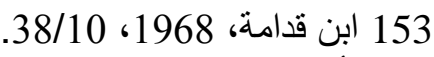
154 أبو داود، 2009، 153، 301/3، 3019، ابن ماجه، (ب.ت)، 25/16، 774/2. 155 البابتري، 154 156 الدسوقي،2010 ، 129/4، ، الابتري، الثربيني، 2001، 477/4،

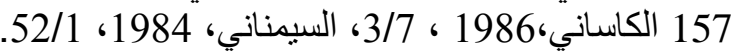

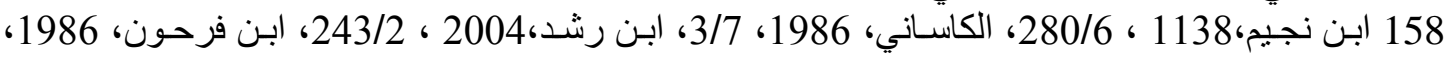




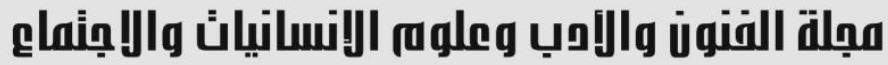

Journal of Arts, Literature, Humanities and Social Sciences www.jalhss.com

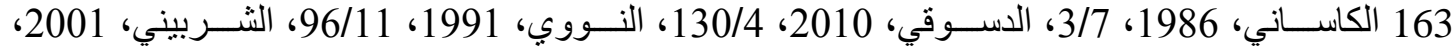

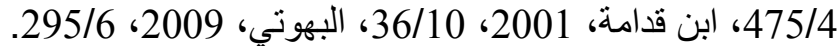

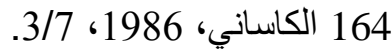
165 الثربيني، 164 النياني، 2001، 375/4،

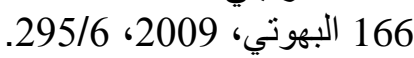
167 الكاساني، 1686، 1986، 3/7، الثربيني، 295/6، 2001، 18/3، 1975/4، البهوتي، 2009، 295/6. 168 الثيرازي، 2018، 378/3، 3786، النووي، 1981، 1991، 96/11، 169 الثيرازي، 2018، 1678، 1978، 378، الثيرازي، 170 ابن فارس، 1979 1979، 133/4 - 134 - 1378 - 135. 171 الزبيدي، 1984، 1979، 19/ اين 19/4 255 - 256. 172 ابن فارس، 173 1979، 133/4 - 1351 - 134 173 الأزهري، 172 فين، 2001، 243/3. 174 ابن منظور، 1714 1414، 95/15، 175 الكاساني، 1986، 1991، 3/7، ابن الهمام، 2003، 2003، 453/1، 176 النووي، 1751، 1968، 196/11، الثربيني، 2001، النيان، 475/4، 177 ابن قدامة، 1768 1968، 178/10، 178 ابن رشد، 2004، 177، 1991، 243/4. 179 النووي، 1991، 196/11، 96/19. 180 المرداوي، (ب.ت.ت)، 177/11 181 181 ابن حزم، 2003، 1971 البردو، 637/10، 182 الماوردي، 1871 1971، 2003، 1986، 183 ابن فرحون، 1986، 1986، 24/1- 25. 184 الثربيني، 183 اين فرن، 2001، 374/4، 185 ابن قدامة، 1868 1968، 36/10،

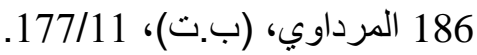

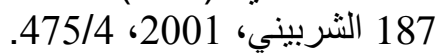
188 ابن القدامة، 1868، 1968، 36/10، 189 الماوردي، 1981 1971، 1995، 1968، 190 الزحيلي، 1995، ص483. 


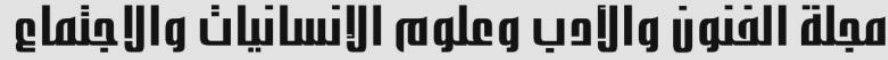

Journal of Arts, Literature, Humanities and Social Sciences
www.jalhss.com

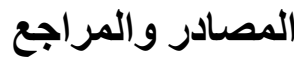

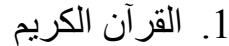

2. ابر اهيم .انيس و آخرون (2004). الدعجم الوسبط. بيروت: دار الفكر.

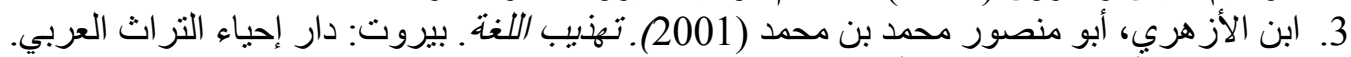

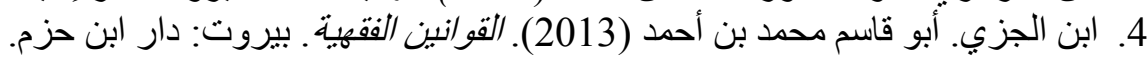

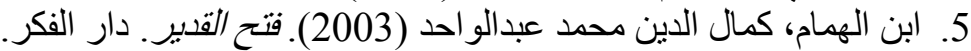

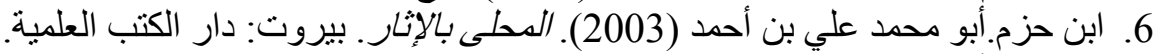

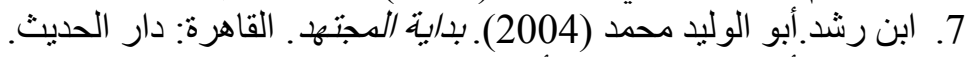

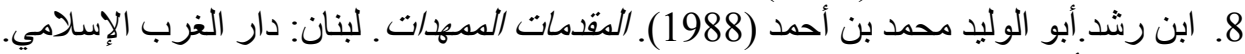

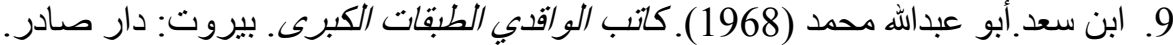

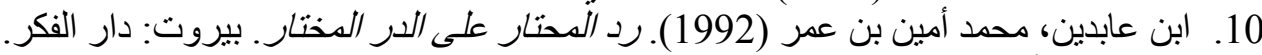

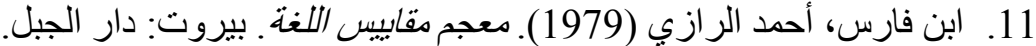

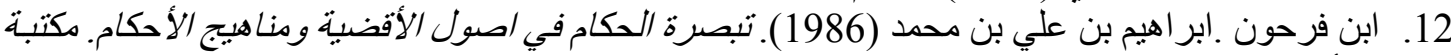
الكلبات الأزهرية.

13. ابن قدامة. أبو محمد موفق الدين عبداله (1968). الدغني. القاهرة: مكتبة القاهرة.

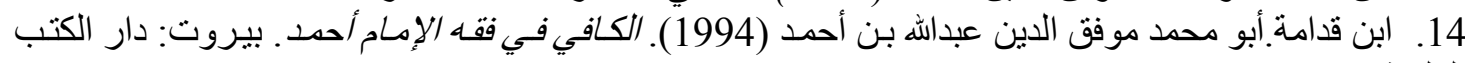
العلمية.

15. ابن كثير. أبو الفداء إسماعيل (1999). تفسبر القرآن العظبي. دار طيبة.

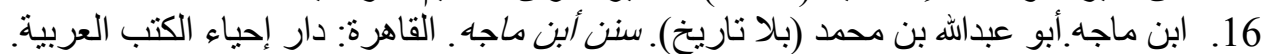

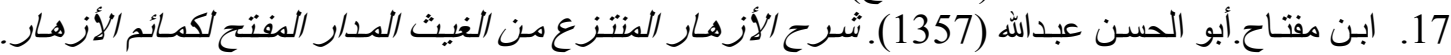
القاهرة: مطبعة الحجازي.

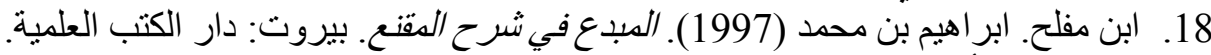

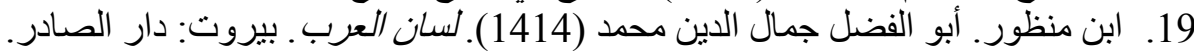

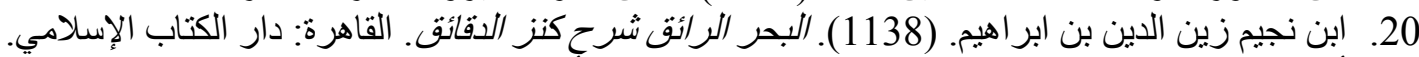

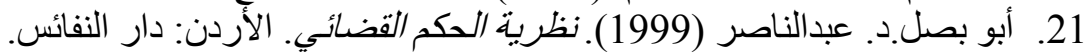

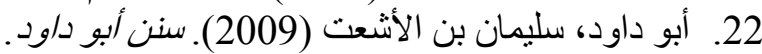

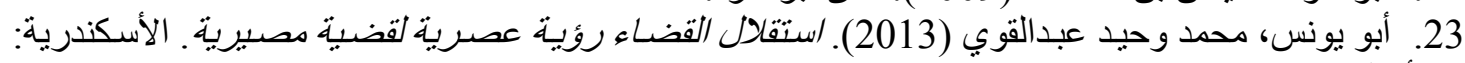

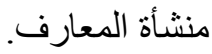

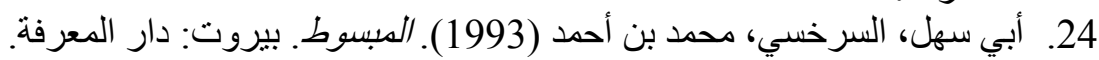

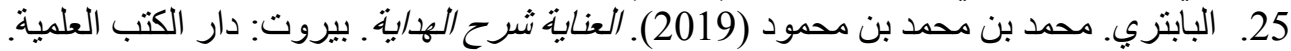

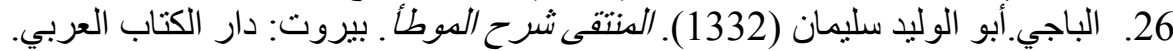

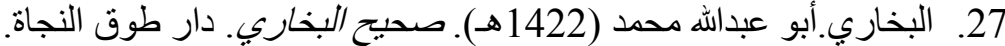

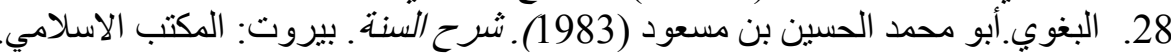

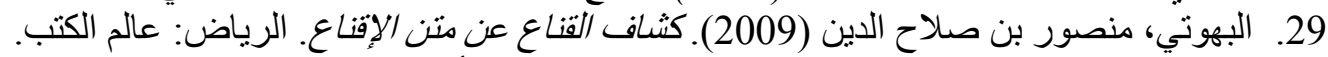

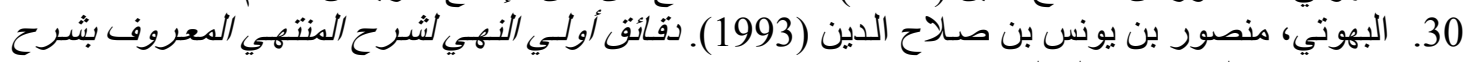
منتهى الإرادات . الرياض، منهور بن عالم الكتب. 31. الترمذي ، محمد بن عيسى بن سورة بن موسى بن الضيحاك (1998). سنن الترمذي. بيروت: دار الغرب

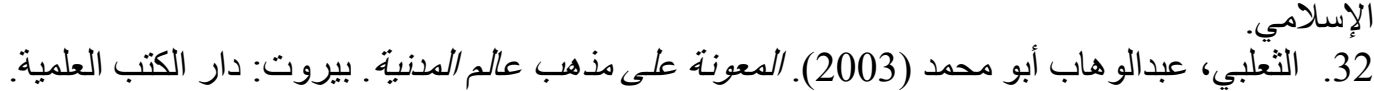

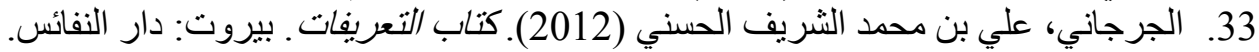

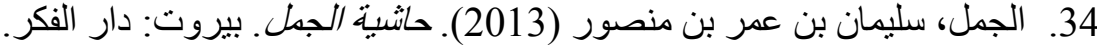

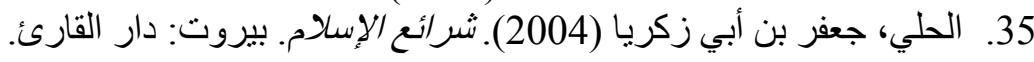




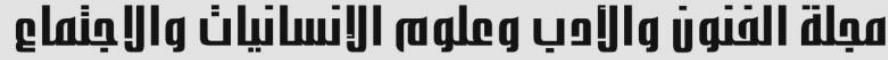

36. د داماد أفند، عبدالرحمن بن محمد (2016). مجدع الأنهر في شرح ملتقى الأبح. دار إحياء التراث العربي.

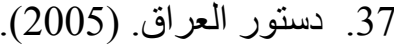

38. 38. الدسوفي، محمد بن أحمد (2010). حاثنية الدسوقي على الثرح الكبير. بيروت: دار الكتب العلمية.

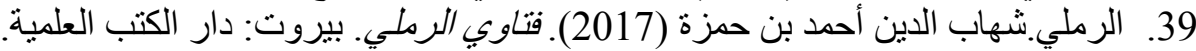

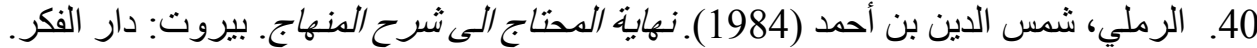

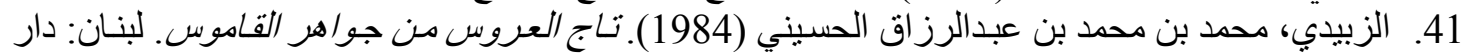

42. الزحيلي.و هبة (1388). الوسيط في اصول الفقه الإسلامي. بيروت: دار الفكر.

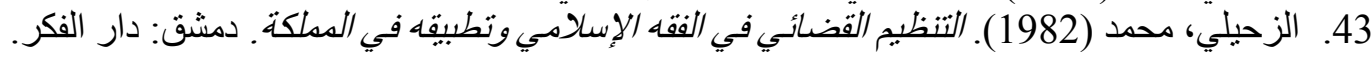

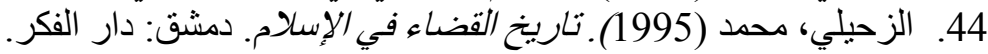

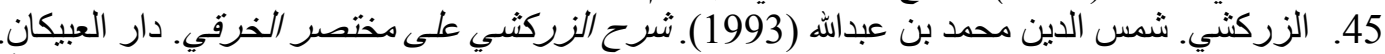
46. الزيلعي، عثمـان بن علي (1313هـ). تببين الحقائق شرح كنز الـقائق. القاهرة: مطبعة الكبرى الأميريـة

بو لاق.

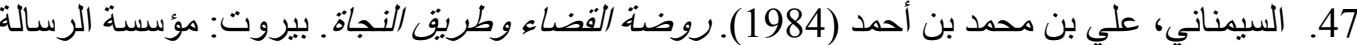

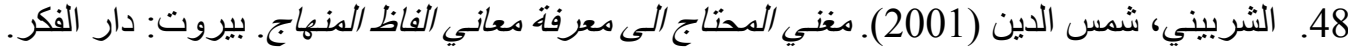

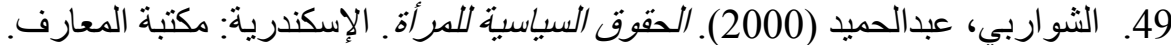

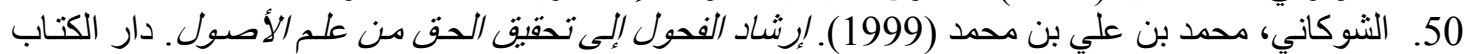

51. ألثوكاني، محمد بن علي محم (2004). السبل الجرار المتدفق على حدائق الأزهار ـ دار بن حزم.

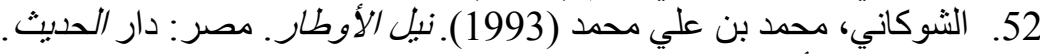

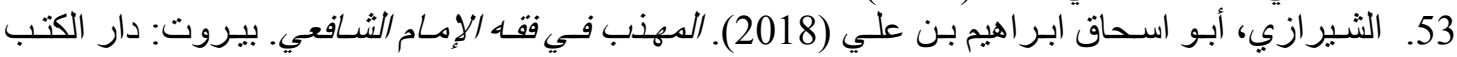

56.

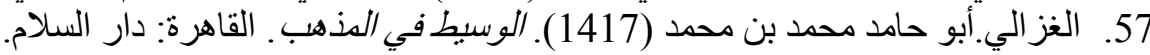

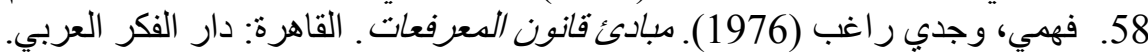

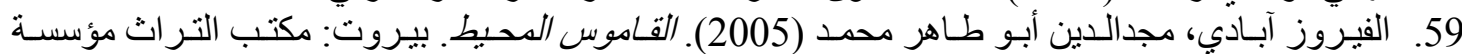

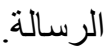

60. القاري، نور الدين علي بن محمد (2005). فتح باب العناية في شرح كتاب النقاية. بيروت: دار إحياء التراث

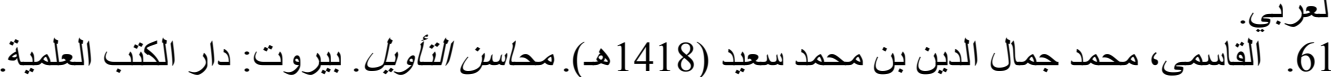
62. قانون الخدمة القضائية. (1945).

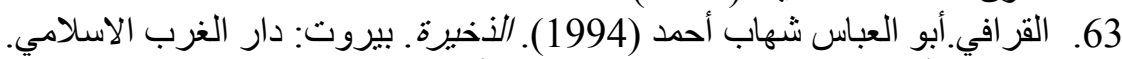

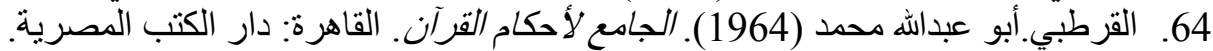

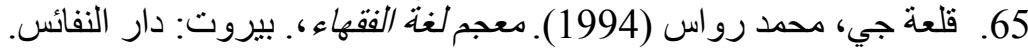

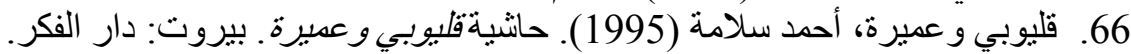

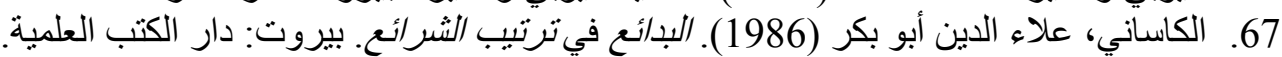

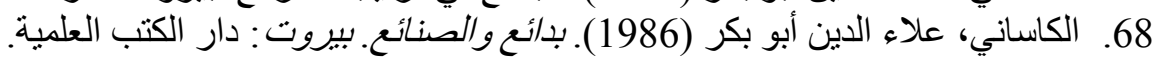

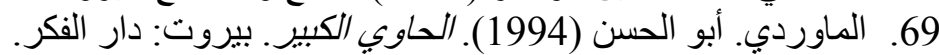

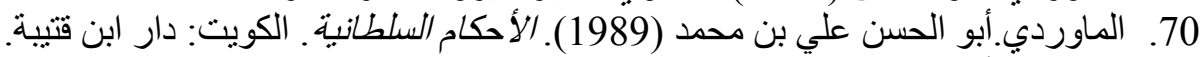

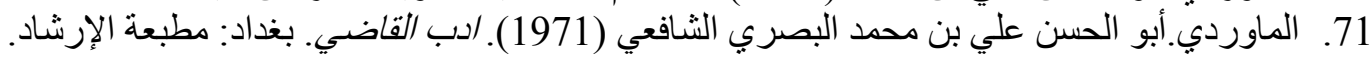




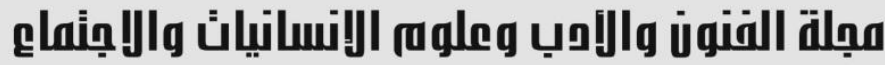

Journal of Arts, Literature, Humanities and Social Sciences www.jalhss.com

72. مبرك، عاثتور (1992). النظرية العامة لقانون القضاء في دولة الإمارات العربية الدتحة. جامعة الإمارات المتحدة.

73. المرتضى، أحمد بن يحيى (2010). البحر الزخار الجامع لمذاهب علماء الأمصار. بيروت: دار الكتب

74. المرداوي، علاء الدين أبو الحسن علي بن سليمان (بلا تاريخ). الإنصاف في معرفة الراجع من الخلاف.

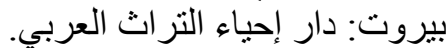

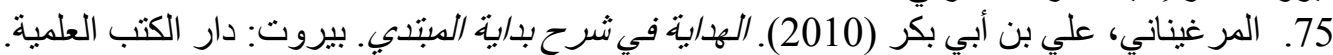

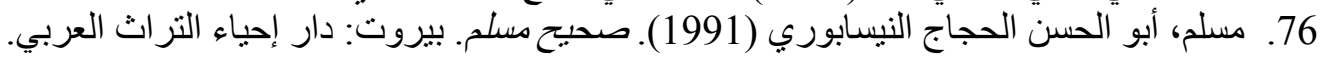

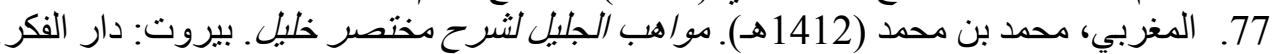

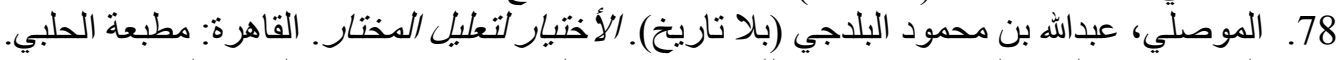

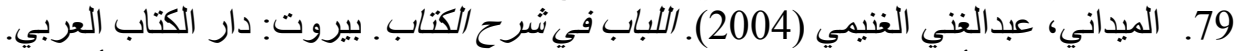

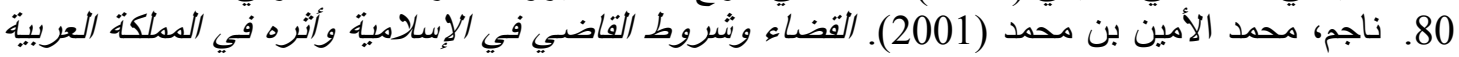

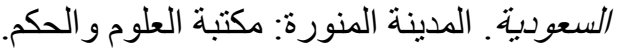

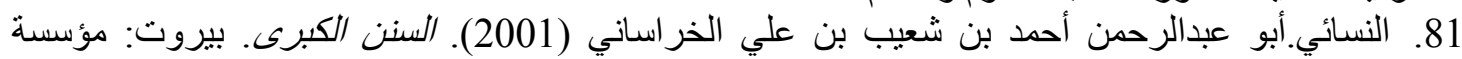

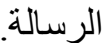

82. النووي. أبو زكريا محي الدين يحيى بن شرف (1991). روضة الطالبين وعمدة الففتبن. بيروت: المكتب

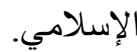
83. النووي.أبو زكريا محي الدين يحيى (2011). الدجموع شرح الدهنب. بيروت: دار الكتب العلمية. 


\section{References}

1. Ibrahim.Anis et al. (2004). The intermediate dictionary. Beirut: House of Thought.

2. Ibn al-Azhari, Abu Mansour Muhammad bin Mohammed (2001). Refine the language. Beirut: The House of The Revival of Arab Heritage.

3. Ibn al-Jizi. Abu Qasim Mohammed bin Ahmed (2013). Doctrinal laws. Beirut: Dar Ibn Hazm.

4. Ibn al-Hammam, Kamal al-Din Mohammed Abdul Wahid (2003). The Almighty opened. House of Thought.

5. Ibn Hazm.Abu Muhammad Ali bin Ahmed (2003). Local with excitement. Beirut: The House of Scientific Books.

6. Ibn Rushd.Abu al-Walid Mohammed (2004). The beginning of the hardworking. Cairo: Dar al-Hadith.

7. Ibn Rushd.Abu al-Walid Mohammed bin Ahmed (1988). Pre-elongated introductions. Lebanon: The House of the Islamic West.

8. Ibn Saad.Abu Abdullah Mohammed (1968). The writer of the great classes. Beirut: Dar Sader.

9. Ibn Abidin, Mohammed Amin bin Omar (1992). Al-Mahtar's reply to the chosen elm. Beirut: House of Thought.

10. Ibn Fares, Ahmad al-Razi (1979). Dictionary of language metrics. Beirut: Dar al-Jabal.

11. Ibn Farhoun. The rulers' insight into the origins of the districts and the approaches of the rulings. Al-Azhar College Library.

12. Son of Adma. Abu Muhammad Muwaffaqaldin Abdullah (1968). Singer. Cairo: Cairo Library.

13. Ibn Qadama. Abu Muhammad Muwaffaq al-Din Abdullah bin Ahmed (1994). Enough in imam Ahmad's jurisprudence. Beirut: The House of Scientific Books.

14. I'm a lot. Abu al-Fida Ismail (1999). Interpretation of the Great Qur'an. A good house.

15. Ibn Magah.Abu Abdullah bin Mohammed (no date). We're the son of Magah. Cairo: The House of The Revival of Arabic Books.

16. Ibn Miftah.Abu al-Hassan Abdullah (1357). Explain the flowers extracted from the open orbit of the flower-blinds. Cairo: Hijazi Press.

17. Ibn Mufleh. Ibrahim bin Mohammed (1997). the creator in the masked explanation. Beirut: The House of Scientific Books.

18. I'm a perspective. Abu fadl Jamal al-Din Muhammad (1414). The tongue of the Arabs. Beirut: Dar al-Issued.

19. Ibn Najim Zainaldin bin Ibrahim. (1138). The sea is a treasure of minutes. Cairo: Islamic Book House.

20. Abu Basal.d. Nasser (1999). The theory of judicial judgment. Jordan: Dar alNafis.

21. Abu Daoud, Suleiman bin Al-Asht (2009). Sinan Abu Daoud. 
22. Abu Younis, Mohammed Wahid Abdul Qawi (2013). The independence of the judiciary is a modern vision of a fateful issue. Alexandria: Knowledge facility.

23. Abu Sahl, Al-Sarkhsi, Mohammed bin Ahmed (1993). Happy. Beirut: Dar alKnowledge.

24. Babtri. Mohammed bin Mohammed bin Mahmoud (2019). Care explain the guidance. Beirut: The House of Scientific Books.

25. Al-Baji. Abu al-Walid Suleiman (1332). The chosen explanation of the foothold. Beirut: Arab Book House.

26. Bukhari. Abu Abdullah Mohammed (1422 Ah). True Bukhari. The life jacket.

27. Al-Bagui.Abu Muhammad al-Hussein bin Massoud (1983). Explain the year. Beirut: Islamic Office.

28. Al-Bahati, Mansour bin Salahaldin (2009). Mask scout for the body of persuasion. Riyadh: The world of books.

29. Al-Bahati, Mansour bin Younis bin Salah al-Din (1993). The first minutes of the end of the year, known as the explanation of the end of the wills. Riyadh: The world of books.

30. Al-Termadi, Muhammad bin Isa bin Sura bin Musa bin Al-Dahak (1998). We're going to be snares. Beirut: The House of the Islamic West.

31. Al-Thalabi, Abdul Wahab Abu Muhammad (2003). aid on the doctrine of the civil world. Beirut: The House of Scientific Books.

32. Al-Jarjani, Ali bin Mohammed al-Sharif al-Hasani (2012). The definition book. Beirut: Dar al-Nafis.

33. Al-Jamal, Suleiman bin Omar bin Mansour (2013). The footnote of the sentences. Beirut: House of Thought.

34. Jewellers, Jaafar bin Abi Zakaria (2004). The canons of Islam. Beirut: Dar alReader.

35. Damad Afund, Abdulrahman bin Mohammed (2016). The complex of rivers in the explanation of the confluence of the abkhaz. The House of Revival of Arab Heritage.

36. Iraq's Constitution. (2005).

37. Al-Desouki, Mohammed bin Ahmed (2010). Al-Desouki's footnote on the big explanation. Beirut: The House of Scientific Books.

38. Al-Ramli.Shihab al-Din Ahmed bin Hamza (2017). Sandy fatwas. Beirut: The House of Scientific Books.

39. Al-Ramli, Shamseddine bin Ahmed (1984). The end of the need to explain the curriculum. Beirut: House of Thought.

40. Zubaidi, Mohammed bin Mohammed bin Abdul Razzaq al-Husseini (1984). The bride's crown of dictionary jewels. Lebanon: Dar al-Hidaya.

41. Al-Zahili. The mediator in the origins of Islamic jurisprudence. Beirut: House of Thought.

42. Al-Zahili, Mohammed (1982). Judicial organization in Islamic jurisprudence and its application in the Kingdom. Damascus: Dar al-Fikr. 
43. Al-Zahili, Mohammed (1995). The history of the judiciary in Islam. Damascus: Dar al-Fikr.

44. Zirkshi. Shamseddine Mohammed bin Abdullah (1993). Explain the zirkshi on the rags. The Obeikan House.

45. Al-Zelai, Osman Bin Ali (1313 Ah). The facts show the explanation of the treasure of the minutes. Cairo: Grand Princely Boulak Press.

46. Al-Simanani, Ali bin Mohammed bin Ahmed (1984). The kindergarten of the judiciary and the way of survival. Beirut: Al-Resala Foundation.

47. Sharbini, Shamseddine (2001). A singer who needs to know the meaning sins of the curriculum. Beirut: House of Thought.

48. Al-Swarabi, Abdul Hamid (2000). Women's political rights. Alexandria: Knowledge Library.

49. Al-Shawkani, Mohammed bin Ali bin Mohammed (1999). Guide the stallion to achieve the right of the science of origins. Arab Book House.

50. Al-Shawkani, Mohammed bin Ali Mohammed (2004). Torrent jars flowing on to the flower gardens. Dar Bin Hazm.

51. Al-Shawkani, Muhammad bin Ali Muhammad (1993). Neal Al-Awtar. Egypt: Dar Al-Hadith.

52. Al-Shirazi, Abu Ishaq Ibrahim bin Ali (2018). The polite in the jurisprudence of Imam Shafi'i. Beirut: Scientific Books House.

53. Al-Sanani Abdul Razzaq. (1403). Classified. Beirut.

54. Al-Tousi, Abu Jaafar Muhammad (1387 AH). Mabsout in the jurisprudence of the Imami. Satisfied Library.

55. Urban. Abu Al-Hussein Yahya bin Abi Al-Khair (2000). The statement in the doctrine of Imam Shafi'i. Jeddah: Dar Al-Minhaj.

56. Al-Ghazali, Abu Hamid Muhammad bin Muhammad (1417). Mediator in the doctrine. Cairo: Dar Al Salam.

57. Fahmy, Wagdy Ragheb (1976). Principles of the law of knowledge. Cairo: Dar Al-Fikr Al-Arabi.

58. Turquoise Abadi, Majd al-Din Abu Taher Muhammad (2005). Surrounding dictionary. Beirut: Heritage Office, the Resala Foundation.

59. Al-Qari, Nuruddin Ali bin Muhammad (2005). Open the door to care in explaining the book of purity. Beirut: House for the Revival of Arab Heritage.

60. Al-Qasimi, Muhammad Jamal Al-Din Bin Muhammad Saeed (1418 AH). Pros of interpretation. Beirut: Scientific Books House.

61. The Judicial Service Law. (1945).

62. Al-Qarafi, Abu al-Abbas Shihab Ahmed (1994). Ammunition. Beirut: Islamic Dar Al Gharb.

63. Al-Qurtubi, Abu Abdullah Muhammad (1964). The whole of the provisions of the Qur'an. Cairo: Egyptian Book House.

64. Castle G, Muhammad Rawas (1994). A dictionary of jurists language. Beirut: Dar Al-Nafees. 
65. Qalioubi and Amira, Ahmed Salama (1995). A footnote to Qalioubi and Amira. Beirut: Dar Al Fikr.

66. Al-Kasani, Aladdin Abu Bakr (1986). Innovations in the arrangement of canons. Beirut: Scientific Books House.

67. Al-Kasani, Aladdin Abu Bakr (1986). Bada'a and Sanayeh. Beirut: Scientific Books House.

68. Al-Mawardi. Abu Al-Hassan (1994). The great container. Beirut: Dar Al Fikr.

69. Al-Mawardi, Abu al-Hasan Ali bin Muhammad (1989). Royal rulings. Kuwait: Dar Ibn Qutaiba.

70. Al-Mawardi, Abu al-Hasan Ali bin Muhammad al-Basri al-Shafi'i (1971). Literature of the judge. Baghdad: Guidance Press.

71. Mubarak, Ashour (1992). General theory of the judiciary law in the United Arab Emirates. United Arab Emirates University.

72. Al-Murtada, Ahmed bin Yahya (2010). Al-Bahr al-Zukhar al-Jami for the doctrines of the scholars 'scholars. Beirut: Scientific Books House.

73. Al-Mardawi, Aladdin Abu Al-Hassan Ali Bin Sulaiman (No History) Fairness in knowing the return from disagreement. Beirut: House for the Revival of Arab Heritage.

74. Al-Marghanani, Ali bin Abi Bakr (2010). Guidance in explaining the beginning of the novice. Beirut: Scientific Books House.

75. Muslim, Abu al-Hasan al-Hajjaj al-Nisaburi (1991). Sahih Muslim. Beirut: House for the Revival of Arab Heritage.

76. The Moroccan, Muhammad bin Muhammad (1412 AH). Galilee's talents to explain Khalil brief. Beirut: Dar Al Fikr.

77. Al-Mawsali, Abdullah bin Mahmoud Al-Baladji (no history). Selection to explain the chosen one. Cairo: Al-Halabi Press.

78. Al-Midani, Abdulghani Al-Ghunaimi (2004). Pulp in explaining the book. Beirut: The Arab Book House.

79. Najim, Muhammad al-Amin bin Muhammad (2001). The judiciary and the conditions of the judge in the Islamic and its impact in the Kingdom of Saudi Arabia. Medina: Library of Science and Governance.

80. Al-Nasa'i, Abu Abd al-Rahman Ahmad bin Shuaib bin Ali al-Khorasani (2001). Sunan major. Beirut: The Resala Foundation.

81. Nuclear. Abu Zakaria Mohiuddin Yahya bin Sharaf (1991). Kindergarten students and mayor of muftis. Beirut: The Islamic Office.

82. Al-Nawawi, Abu Zakaria Mohiuddin Yahya (2011). Total polite explanation. Beirut: Scientific Books House. 